\title{
Using FTIR measurements of stratospheric composition to identify midlatitude polar vortex intrusions over Toronto
}

\author{
C. Whaley, ${ }^{1}$ K. Strong, ${ }^{1}$ C. Adams,,${ }^{1,2}$ A. E. Bourassa,${ }^{2}$ W. H. Daffer,${ }^{3}$ D. A. Degenstein, ${ }^{2}$ \\ H. Fast, ${ }^{4}$ P. F. Fogal, ${ }^{4}$ G. L. Manney, ${ }^{5,6}$ R. L. Mittermeier, ${ }^{4}$ B. Pavlovic, ${ }^{1,7}$ and A. Wiacek ${ }^{8}$ \\ Received 18 July 2013; revised 28 October 2013; accepted 8 November 2013; published 22 November 2013.
}

[1] Using 11 years of trace gas measurements made at the University of Toronto Atmospheric Observatory $\left(43.66^{\circ} \mathrm{N}, 79.40^{\circ} \mathrm{W}\right)$ and Environment Canada's Centre for Atmospheric Research Experiments $\left(44.23^{\circ} \mathrm{N}, 79.78^{\circ} \mathrm{W}\right)$, along with derived meteorological products, we identify a number of polar intrusion events, which are excursions of the polar vortex or filaments from the polar vortex extending down to midlatitudes. These events are characterized by enhanced stratospheric columns $(12-50 \mathrm{~km})$ of hydrogen fluoride (HF), by diminished stratospheric columns of nitrous oxide $\left(\mathrm{N}_{2} \mathrm{O}\right)$, and by a scaled potential vorticity above $1.2 \times 10^{-4} \mathrm{~s}^{-1}$. The events comprise $16 \%$ of winter/spring (November to April inclusive) Fourier transform infrared (FTIR) spectroscopic measurements from January 2002 to March 2013, and we find at least two events per year. The events are corroborated by Modèle Isentrope du transport Méso-échelle de l'Ozone Stratosphérique par Advection, Modern-Era Retrospective Analysis for Research and Applications potential vorticity maps, and Global Modeling Initiative $\mathrm{N}_{2} \mathrm{O}$ maps. During polar intrusion events, the stratospheric ozone $\left(\mathrm{O}_{3}\right)$ columns over Toronto are usually greater than when there is no event. Our $\mathrm{O}_{3}$ measurements agree with the Optical Spectrograph and Infrared Imaging System satellite instrument and are further verified with the Earth Probe Total Ozone Mapping Spectrometer and Ozone Monitoring Instrument satellite observations. We find six cases out of 53 for which chemical $\mathrm{O}_{3}$ depletion within the polar vortex led to a reduction in stratospheric $\mathrm{O}_{3}$ columns over Toronto. We have thus identified a dynamical cause for most of the winter/spring variability of stratospheric trace gas columns observed at our midlatitude site. While there have been a number of prior polar intrusion studies, this is the first study to report in the context of 11 years of ground-based FTIR column measurements, providing insight into the frequency of midlatitude polar vortex intrusions and observations of upper stratospheric $(25-50 \mathrm{~km})$ intrusions. It is also the first to present $\mathrm{HF}$ measurements during multiple polar intrusions, which provided an excellent tracer for their identification.

Citation: Whaley, C., et al. (2013), Using FTIR measurements of stratospheric composition to identify midlatitude polar vortex intrusions over Toronto, J. Geophys. Res. Atmos., 118, 12,766-12,783, doi:10.1002/2013JD020577.

\section{Introduction}

[2] The stratospheric polar vortex is a large low-pressure system that persists over the winter pole for many months, characterized by low temperatures, high potential vorticity (PV), and high winds near its boundary. The descent

\footnotetext{
${ }^{1}$ Department of Physics, University of Toronto, Toronto, Ontario, Canada.

${ }^{2}$ Department of Physics and Engineering Physics, University of Saskatchewan, Saskatoon, Saskatchewan, Canada.
}

Corresponding author: C. Whaley, Whaley, Department of Physics, University of Toronto, 60 St. George Street, Toronto, ON M5S 1A7, Canada. (cwhaley@atmosp.physics.utoronto.ca)

(C)2013. American Geophysical Union. All Rights Reserved. 2169-897X/13/10.1002/2013JD020577 of air within the polar vortex and its relative isolation result in a distinctive chemical composition; hydrogen chloride $(\mathrm{HCl})$, hydrogen fluoride $(\mathrm{HF})$, and ozone $\left(\mathrm{O}_{3}\right)$ total and stratospheric columns tend to be enhanced because when stratospheric gases descend in altitude, they main-

\footnotetext{
${ }^{3}$ Jet Propulsion Laboratory, California Institute of Technology, Pasadena, California, USA

${ }^{4}$ Air Quality Research Division, Atmospheric Science and Technology Directorate, Science and Technology Branch, Environment Canada, Toronto, Ontario, Canada.

${ }^{5}$ NorthWest Research Associates, Socorro, New Mexico, USA.

${ }^{6}$ Department of Physics, New Mexico Institute of Mining and Technology, Socorro, New Mexico, USA.

${ }^{7}$ Department of Physics, University of Guelph, Guelph, Ontario, Canada.

${ }^{8}$ Environmental Science, Saint Mary's University, Halifax, Nova Scotia, Canada.
} 
tain their mixing ratio but number densities increase. $\mathrm{O}_{3}$ columns in particular are increased (in the absence of chemical $\mathrm{O}_{3}$ loss) during winter because of poleward transport from the tropics and then descent via the BrewerDobson circulation. Similarly, the descent of long-lived tropospheric gases like nitrous oxide $\left(\mathrm{N}_{2} \mathrm{O}\right.$, which is destroyed in the stratosphere) results in diminished columns of $\mathrm{N}_{2} \mathrm{O}$ in the polar vortex [Schoeberl et al., 1992, 1995; Brasseur et al., 1999].

[3] The northern polar vortex typically extends down to about $65^{\circ}-68^{\circ} \mathrm{N}$ in latitude when centered near the North Pole, and its edge has been defined in a number of ways: using PV gradients and wind speeds [e.g., Nash et al., 1996], the Q-diagnostic method [e.g., Harvey et al., 2002], or scaled PV [e.g., Manney et al., 2007]. In the spring, when the vortex breaks up, parts or fragments of a highly distorted vortex can extend to much lower latitudes [Waugh et al., 1994; Orsolini, 1995; Hauchecorne et al., 2002]. Excursions of the polar vortex to midlatitudes have been observed and modeled [Godin et al., 2002; Marchand et al., 2003; Konopka et al., 2003; Durry and Hauchecorne, 2005; Duchatelet et al., 2009], as have filaments breaking off the polar vortex and extending to the midlatitudes [Leovy et al., 1985; Andrews et al., 1987; Pierce and Fairlie, 1993; Manney et al., 1998, 2000; Newman et al., 1996; Orsolini et al., 1998; Godin et al., 2002; Hauchecorne et al., 2002; Marchand et al., 2003; Millard et al., 2003; Tripathi et al., 2006]. Filaments are formed when the vortex edge is deformed by meridional winds induced by planetary Rossby waves breaking [McIntyre and Palmer, 1984; Waugh et al., 1994] and subtropical anticyclones [Pierce and Fairlie, 1993]. The filaments are stretched out by the meridional gradient of the zonal wind over the course of a few days [Pierce and Fairlie, 1993; Marchand et al., 2003].

[4] The previous studies of polar intrusion events mentioned above used measurements of $\mathrm{O}_{3}, \mathrm{CH}_{4}, \mathrm{~N}_{2} \mathrm{O}, \mathrm{HCl}$, $\mathrm{H}_{2} \mathrm{O}, \mathrm{CO}_{2}, \mathrm{COF}_{2}$, and CFCs from lidars, ozonesondes, aircraft-borne photometry and spectroscopy, groundbased spectroscopy, and balloon-borne in situ instruments, as well as reverse domain-filling trajectory calculations [e.g., Sutton et al., 1994; Schoeberl and Newman, 1995; Manney et al., 1998, 2000], and 3-D chemical transport models (CTMs) such as the Single Layer Isentropic Model of Chemistry And Transport, the Chemical Lagrangian Model of the Stratosphere, and the Modèle Isentrope du transport Méso-échelle de l'Ozone Stratosphérique par Advection (MIMOSA) to detect and model polar intrusion events. There have been several studies of polar intrusion events observed over Europe [Orsolini et al., 1997, 1998; Godin et al., 2002; Durry and Hauchecorne, 2005], but only a few over North America (and Hawaii) [Newman et al., 1996; Manney et al., 1998; Tripathi et al., 2006].

[5] Polar intrusion events can have varying, but significant, effects on midlatitude $\mathrm{O}_{3}$ columns. When the vortex is cold and stable, conditions are favorable for chemical $\mathrm{O}_{3}$ depletion but are unfavorable for filamentation, and thus to transport to midlatitudes [Hauchecorne et al., 2002; Millard et al., 2003]. Conversely, when a stratospheric warming occurs, the polar vortex is more likely to break up and extend to midlatitudes [Waugh et al., 1994; Hauchecorne et al., 2002]. It has been reported that up to $50 \%$ of midlatitude $\mathrm{O}_{3}$ volume mixing ratio (VMR) decreases at $475 \mathrm{~K}$ can be accounted for by intrusions of $\mathrm{O}_{3}$-poor polar air to midlatitudes [Marchand et al., 2003; Millard et al., 2003]. However, increases in midlatitude $\mathrm{O}_{3}$ due to polar vortex intrusions have also been reported [e.g., Godin et al., 2002; Tripathi et al., 2006].

[6] The goals of the present study are to use long-term measurements to estimate how often polar intrusion events occur over the Toronto region (a large metropolitan area of about six million people) and to determine whether these polar intrusion events can explain some of the variability in the time series of trace gases observed at this midlatitude location. This study is the first to report polar intrusion events over southern Canada, using long-term ground-based measurements of stratospheric partial columns $(12-50 \mathrm{~km})$ of $\mathrm{HF}$ and $\mathrm{N}_{2} \mathrm{O}$ obtained by Fourier transform infrared (FTIR) spectroscopy to identify their occurrence. Given that there was unprecedented Arctic $\mathrm{O}_{3}$ loss in spring 2011 [Balis et al., 2011; Manney et al., 2011; Adams et al., 2012; Lindenmaier et al., 2012], we are also interested in determining whether $\mathrm{O}_{3}$ columns above Toronto were diminished during 2011 polar intrusion events.

[7] $\mathrm{HF}$ is an excellent dynamical tracer for the polar vortex because it has a long lifetime, and as mentioned previously, it has a greater density inside the polar vortex [Chipperfield et al., 1997; Toon et al., 1999; Mellqvist et al., 2002; Coffey et al., 2008]. Therefore, we examine 11 years of Toronto FTIR data (January 2002 to March 2013), looking for outliers of $\mathrm{HF}$ as an indicator of polar air. Polar intrusions are then either confirmed or discounted as the source of the outliers using scaled potential vorticity, models, and satellite observations, which provide more spatial coverage, showing the polar vortex structure at the time of the HF outlier.

[8] This paper is organized as follows. The next section briefly describes our measurements. Section 3 describes the MIMOSA model and the Modern-Era Retrospective Analysis for Research and Applications (MERRA) data assimilation system from which PV has been used to confirm the occurrence of polar intrusion events. The Global Modeling Initiative (GMI) CTM and derived meteorological products (DMPs) are also described in this section. This is followed by a discussion of our results (section 4) and conclusions (section 5).

\section{Measurements}

\subsection{TAO FTIR Spectrometer}

[9] The primary measurements used in this study are made by a ground-based, high-resolution $\left(0.004 \mathrm{~cm}^{-1}\right)$ Bomem DA8 FTIR spectrometer at the University of Toronto Atmospheric Observatory (TAO), $43.66^{\circ} \mathrm{N}$, $79.4^{\circ} \mathrm{W}, 174$ meters above sea level (masl) [Wiacek et al., 2007]. The TAO FTIR spectrometer was installed in late 2001 and has been operational for daily measurements, weather permitting, since May 2002. TAO became a site in the Network for Detection of Atmospheric Composition Change (NDACC) in 2004. We retrieve total and partial column amounts of $\mathrm{HCl}, \mathrm{HF}, \mathrm{O}_{3}$, and $\mathrm{N}_{2} \mathrm{O}$ using the optimal estimation method [Rodgers, 2000] implemented with the SFIT2 [Rinsland et al., 1998; Pougatchev et al., 1995] v3.94 algorithm and the High-resolution Transmission molecular absorption database 2008 spectral line list [Rothman et al., 2009]. Temperature and pressure profiles are obtained from 
WHALEY ET AL.: POLAR INTRUSIONS OVER TORONTO

Table 1. TAO and CARE FTIR Retrieval Parameters ${ }^{\mathrm{a}}$

\begin{tabular}{|c|c|c|c|c|c|c|}
\hline Species & Microwindow(s) $\left(\mathrm{cm}^{-1}\right)$ & Interfering Species & SNR & $\mathbf{S}_{a}$ & DOFS & $\begin{array}{c}\text { Partial } \\
\text { Column Errors }\end{array}$ \\
\hline $\mathrm{HF}$ & $4038.86-4039.05$ & $\mathrm{H}_{2} \mathrm{O}$ & 250 & $20 \%$ & $1.2 / 1.2$ & $3.0 \% / 1.1 \%$ \\
\hline $\mathrm{HCl}$ & $\begin{array}{l}2727.73-2727.83 \\
2775.70-2775.80 \\
2925.80-2926.00\end{array}$ & $\begin{array}{c}\mathrm{O}_{3}, \mathrm{HDO} \\
\mathrm{N}_{2} \mathrm{O}, \mathrm{O}_{3} \\
\mathrm{NO}_{2}, \mathrm{O}_{3}, \mathrm{CH}_{4}\end{array}$ & 300 & $10-40 \%$ & $3.5 / 3.2$ & $3.5 \% / 2.0 \%$ \\
\hline $\mathrm{N}_{2} \mathrm{O}$ & $\begin{array}{l}2481.30-2482.60 \\
2526.40-2528.20 \\
2537.85-2538.80 \\
2540.10-2540.70\end{array}$ & $\begin{array}{l}\mathrm{CO}_{2}, \mathrm{CH}_{4}, \mathrm{O}_{3}, \mathrm{H}_{2} \mathrm{O}, \mathrm{HDO} \\
\mathrm{CO}_{2}, \mathrm{CH}_{4}, \mathrm{O}_{3}, \mathrm{H}_{2} \mathrm{O}, \mathrm{HDO} \\
\mathrm{CO}_{2}, \mathrm{CH}_{4}, \mathrm{O}_{3}, \mathrm{H}_{2} \mathrm{O}, \mathrm{HDO} \\
\mathrm{CO}_{2}, \mathrm{CH}_{4}, \mathrm{O}_{3}, \mathrm{H}_{2} \mathrm{O}, \mathrm{HDO}\end{array}$ & 100 & $20 \%$ & $3.7 / 1.8$ & $9.0 \% / 1.8 \%$ \\
\hline $\mathrm{O}_{3}(3051)$ & $3051.29-3051.90$ & $\mathrm{H}_{2} \mathrm{O}, \mathrm{CH}_{4}, \mathrm{HDO}, \mathrm{CH}_{3} \mathrm{D}$ & 100 & $20 \%$ & $2.5 / 2.1$ & $8.6 \% / 1.5 \%$ \\
\hline $\mathrm{O}_{3}(1000)$ & $1000.00-1000.50$ & $\mathrm{H}_{2} \mathrm{O}, \mathrm{CO}_{2}, \mathrm{CH}_{4}, \mathrm{O}_{3}$ isotopes & 35 & $20 \%$ & $4.8 / 3.2$ & $5.4 \% / 1.1 \%$ \\
\hline
\end{tabular}

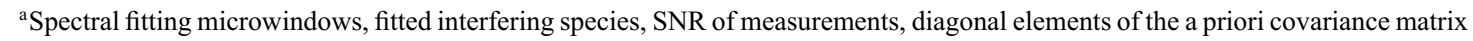
$\left(\mathbf{S}_{a}\right)$, DOFS for total/stratospheric $(12-50 \mathrm{~km})$ columns, and errors (total/random) on the $12-50 \mathrm{~km}$ partial columns.

the National Centers for Environmental Prediction Climate Prediction Center meteorological data product (hyperion. gsfc.nasa.gov/Data services/automailer/index.html) for $z=$ $0-50 \mathrm{~km}$ and the mean of a 40 year run (1980-2020) of the Whole Atmosphere Chemistry Climate Model (WACCM, version 6) [Eyring et al., 2007] for Toronto (J. Hannigan, NCAR, personal communication, 2012) for $z=50-120 \mathrm{~km}$.

[10] The $\mathrm{TAO} \mathrm{O}_{3}, \mathrm{HCl}$, and $\mathrm{N}_{2} \mathrm{O}$ measurements have been validated during a number of ground-based and satellite intercomparison campaigns [Wiacek et al., 2007; Wunch et al., 2007; Taylor et al., 2007, 2008]. We have since updated some retrieval parameters such as the a priori VMR profiles, which now come from the mean of the same 40 year WACCM run mentioned above. The spectral microwindows have been updated to those recommended by the Network for Detection of Atmospheric Composition Change Infrared Working Group (NDACC-IRWG) harmonization initiative (which seeks to have all NDACC-IRWG sites use the same retrieval parameters for consistency, www.acd.ucar. edu/irwg/), except those for $\mathrm{O}_{3}$. One $\mathrm{O}_{3}$ microwindow used for this study is $1000-1005 \mathrm{~cm}^{-1}$, which is the IRWG recommendation. But for better temporal coverage for our data set, we also include the $3051.29-3051.90 \mathrm{~cm}^{-1} \mathrm{O}_{3}$ microwindow. Both microwindows provide ample information for stratospheric partial columns, no bias, and have been used in previous studies (e.g., see Kagawa et al. [2007] for the 3051 $\mathrm{cm}^{-1}$ microwindow and Lindenmaier et al. [2010] for the $1000 \mathrm{~cm}^{-1}$ microwindow). All microwindows used in this study, except that for $\mathrm{HF}$ and the $1000 \mathrm{~cm}^{-1}$ microwindow for $\mathrm{O}_{3}$, fall in the spectral range of the same filter (NDACC FTIR filter 3) and thus are measured at the same time. The microwindow for $\mathrm{HF}$ retrievals falls in a different spectral filter (NDACC FTIR filter 1), and the $1000 \mathrm{~cm}^{-1}$ microwindow falls in NDACC filter 6 . Thus, the $\mathrm{HF}$ and some $\mathrm{O}_{3}$ measurements occur at slightly different times and often have fewer measurements per day than the other species.

[11] Table 1 lists the retrieval parameters used and the resulting median degrees of freedom for signal (DOFS, defined as the trace of the averaging kernel matrix) [Rodgers, 2000 ] for the total columns and the $12-50 \mathrm{~km}$ stratospheric partial columns over the 12 year data set. Table 1 also lists the total errors on the $12-50 \mathrm{~km}$ partial columns and the random component of the errors (discussed below). The signal-to-noise ratios (SNR) of the measurements (related to the diagonal elements of the error covariance matrix,
$\mathbf{S}_{e}$, with no off-diagonal elements) [Wiacek et al., 2007] were chosen based on a root-mean-square fitting residual versus SNR trade-off curve for each species. The a priori covariance matrices ( $\mathbf{S}_{a}$, diagonal elements of corresponding standard deviation listed in Table 1) for each species were chosen based on the variance seen in the respective Halogen Occultation Experiment observations over Toronto [Wiacek et al., 2007], except for $\mathrm{N}_{2} \mathrm{O}$, which was based on Michelson Interferometer for Passive Atmospheric Sounding observations, and we use a Gaussian correlation length of $4 \mathrm{~km}$ for off-diagonal elements of $\mathbf{S}_{a}$ [Wiacek, 2006; Wiacek et al., 2007].

[12] The stratospheric columns (defined as $12-50 \mathrm{~km}$ in this study) of $\mathrm{HF}, \mathrm{HCl}, \mathrm{O}_{3}$ (at $3051 \mathrm{~cm}^{-1}$ and $1000 \mathrm{~cm}^{-1}$ ), and $\mathrm{N}_{2} \mathrm{O}$ have errors of $3 \%, 3.5 \%, 8.6 \%, 5.4 \%$, and $9 \%$, respectively. These are total error budgets that include spectroscopic errors (line width and line intensity, which together are the dominant sources of error), measurement, smoothing, temperature, interference, and solar zenith angle errors calculated as described in Lindenmaier et al. [2010]. When only random errors (eliminating spectroscopic errors which are systematic) are taken into account (i.e., when discussing changes within the time series), the errors are $1.1 \%, 2.0 \%$, $1.5 \%, 1.1 \%$, and $1.8 \%$ for $\mathrm{HF}, \mathrm{HCl}, \mathrm{O}_{3}$ (at $3051 \mathrm{~cm}^{-1}$ and $1000 \mathrm{~cm}^{-1}$ ), and $\mathrm{N}_{2} \mathrm{O}$, respectively. These are summarized in Table 1.

[13] Because FTIR solar absorption measurements can only be made when skies are clear, at TAO we typically have 80 to 100 days of measurements per year, with greater coverage in the summertime and a greater number of measurement days in recent years due to improvements in efficiency and instrument maintenance.

[14] Detecting polar vortex intrusions using ground-based FTIR spectroscopy has few advantages over the other measurement techniques described in section 1: it can be used to measure multiple trace gases simultaneously, or nearly so, including HF; it has sensitivity extending to the upper stratosphere; and it can provide data sets that cover long time periods (e.g., semiregular measurements at TAO since 2002).

\subsubsection{FTIR Sensitivity to the Stratosphere}

[15] The TAO averaging kernels characterize the vertical information contained in the FTIR retrievals [Rodgers, 2000]. Figure 1 shows typical TAO VMR averaging kernels for total column $\mathrm{HF}, \mathrm{HCl}, \mathrm{O}_{3}$, and $\mathrm{N}_{2} \mathrm{O}$ retrievals along 


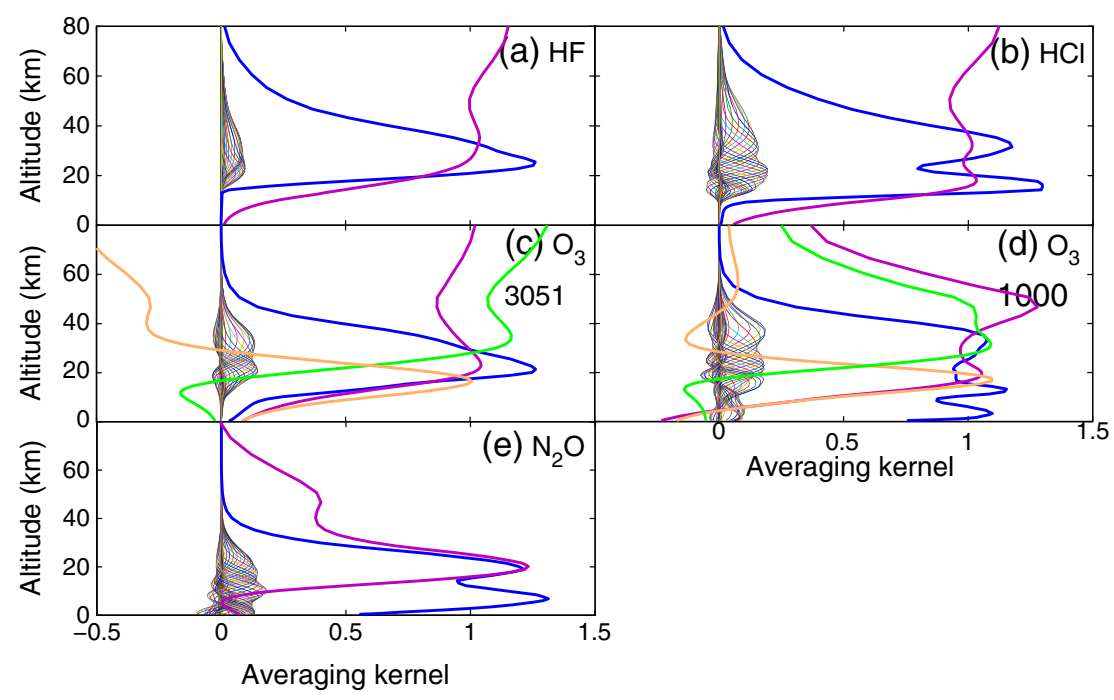

Figure 1. VMR averaging kernels (thin colored lines), sensitivity (thick blue lines), and stratospheric partial column (12-50 km) averaging kernels (thick purple lines) for TAO retrievals of (a) HF, (b) $\mathrm{HCl}$, (c) $\mathrm{O}_{3}$ (from $3051 \mathrm{~cm}^{-1}$ microwindow), (d) $\mathrm{O}_{3}$ (from $1000 \mathrm{~cm}^{-1}$ microwindow), and (e) $\mathrm{N}_{2} \mathrm{O}$. In Figures $1 \mathrm{c}$ and $1 \mathrm{~d}$, the $\mathrm{O}_{3}$ partial column averaging kernels for $12-23 \mathrm{~km}$ and $23-50 \mathrm{~km}$ are shown in orange and green, respectively.

with the stratospheric partial column $(12-50 \mathrm{~km})$ averaging kernels, which are equal to the VMR averaging kernels weighted by the density, summed over the layers of interest. The weighting by density, along with some smearing of information to higher altitudes, is what causes the partial column averaging kernel to increase at higher altitudes for $\mathrm{HF}, \mathrm{HCl}$, and $\mathrm{O}_{3}$. Also plotted is the sensitivity, $S_{k}$, at each altitude, $k$ (equation (1)) [Vigouroux et al., 2008]:

$$
S_{k}=\sum_{i} A_{k i}
$$

where $A$ is the averaging kernel matrix and the summation is over the $i$ elements of the $k$ th row. When the sensitivity is above 0.5 , it means that the measurements are contributing more than $50 \%$ to the retrieved profile (with the rest coming from the a priori profile). The $\mathrm{HF}, \mathrm{HCl}$, and $\mathrm{O}_{3}$ retrievals all have excellent sensitivity $\left(S_{k} \sim 1\right)$ in the stratosphere. While the $\mathrm{N}_{2} \mathrm{O}$ retrievals have more sensitivity to the troposphere, $S_{k}$ is $>0.5$ throughout most of the stratosphere, and the DOFS is 1.8 for the $12-50 \mathrm{~km}$ partial columns (see Table 1). Thus, the $\mathrm{N}_{2} \mathrm{O}$ retrievals have good sensitivity in the stratosphere as well.

[16] About $80 \%$ of the stratospheric columns $(12-50 \mathrm{~km})$ come from $12-35 \mathrm{~km}(380-1000 \mathrm{~K}), 12-32 \mathrm{~km}(380-850$ $\mathrm{K}), 12-20 \mathrm{~km}(380-500 \mathrm{~K})$, and $12-32 \mathrm{~km}(380-850 \mathrm{~K})$, for $\mathrm{HF}, \mathrm{HCl}, \mathrm{N}_{2} \mathrm{O}$, and $\mathrm{O}_{3}$, respectively.

\subsection{CARE FTIR Spectrometer}

[17] Environment Canada's Centre for Atmospheric Research Experiments (CARE) is located at Egbert, Ontario, about $80 \mathrm{~km}$ north of Toronto at $44.23^{\circ} \mathrm{N}, 79.78^{\circ} \mathrm{W}$, 251 masl. Measurements with a Bomem DA8 FTIR spectrometer began at CARE in January 1996, although we only examine the data set from 2002 onwards when we have complementary TAO data. The CARE DA8 has the same characteristics as the DA8 spectrometer at TAO, and HF,
$\mathrm{HCl}, \mathrm{O}_{3}$, and $\mathrm{N}_{2} \mathrm{O}$ stratospheric columns were retrieved in the same way as described in section 2.1 and using the parameters in Table 1. The errors of the Egbert stratospheric columns are also the same as those for TAO. The Egbert results complement those from TAO, as the two sites are generally close enough to be looking at the same stratospheric air. That is, the two sites are less than $1^{\circ}$ apart, which is the resolution of the MIMOSA and MERRA maps. Theoretically though, a small filament could be over one site and not the other.

[18] The frequency of Egbert measurements varies greatly from year to year due to the availability of staff and instrument downtime for maintenance, repair, and upgrades. The greatest number of measurement days (about 30 per year) occurred during 2002-2007, and there were very few in 2008-2010 and none in 2011-2013.

\subsection{OSIRIS}

[19] We use $\mathrm{O}_{3}$ partial columns $(12-50 \mathrm{~km})$ from the Optical Spectrograph and infrared Imaging System (OSIRIS) on the Odin satellite [Llewellyn et al., 2004; Murtagh et al., 2002] over the Toronto region (within $600 \mathrm{~km}$, or approximately $5^{\circ}$, of Toronto, $43.66^{\circ} \mathrm{N}, 79.40^{\circ} \mathrm{W}$ ) to complement our TAO and CARE $\mathrm{O}_{3}$ time series. These data are available from November 2001 to the present and have previously compared favorably to TAO $\mathrm{O}_{3}$ [Taylor et al., 2007]. We also use OSIRIS $\mathrm{O}_{3}$ maps centered over the North Pole to examine $\mathrm{O}_{3}$ distributions at the time of the observed polar intrusion events. To produce polar maps at fixed potential temperature levels, data were passed through a Gaussian filter with a $12^{\circ}$ full width at half maximum onto a $5^{\circ} \times 5^{\circ}$ latitude/longitude grid. For each grid point, the angular distance between the grid point and the OSIRIS measurements was calculated. Weights based on the angular distance between the measurements and the grid point were calculated using the Gaussian function. The weighted mean of 
OSIRIS measurements at the given grid point was then calculated. If the sum of weights at a given grid point was $<1$, the grid point was left empty. The Gaussian filter and the interpolation grid were tested for various cases to ensure that smoothing and interpolation did not introduce any spurious features in the maps. The $5^{\circ}$ filter provided the best balance between showing the details in the OSIRIS measurements and not leading to large gaps in the figure. The choice of interpolation grid did not have a significant impact on the maps for the measurement dates considered.

[20] OSIRIS observes limb radiance profiles of scattered sunlight from 280 to $800 \mathrm{~nm}$ at $1 \mathrm{~nm}$ spectral resolution, with a $1 \mathrm{~km}$ vertical field of view over tangent altitudes ranging from approximately 10 to $100 \mathrm{~km}$. Vertical profiles are obtained every $5^{\circ}$ along the sun-synchronous satellite track inclined at $98^{\circ}$ and are nominally measured in the orbit plane, limiting the maximum latitude coverage to $82^{\circ}$. Approximately 15 orbits are performed each day, providing measurements every $24^{\circ}$ of longitude at the equator and much denser coverage at high latitudes. OSIRIS measures within $600 \mathrm{~km}$ of Toronto several times per day and measures $\mathrm{O}_{3}$, aerosol, and nitrogen dioxide $\left(\mathrm{NO}_{2}\right)$ during the Northern Hemisphere spring and summer (starting in mid to late February for Toronto).

[21] The SaskMART (Multiplicative Algebraic Reconstruction Technique) [Degenstein et al., 2009] v5.01 $\mathrm{O}_{3}$ product was used in this study. $\mathrm{O}_{3}$ absorption information in both the UV and visible parts of the spectrum is used to retrieve number density profiles from $60 \mathrm{~km}$ to the cloud tops (down to a minimum of $10 \mathrm{~km}$ in the absence of clouds). The $12-50 \mathrm{~km}$ partial columns were derived from these number density profiles. OSIRIS $\mathrm{O}_{3}$ mixing ratios, calculated from number density and neutral density profiles, are also available. SaskMART v5.0x $\mathrm{O}_{3}$ has been well validated, with less than $2 \%$ bias compared to other satellite measurements [Degenstein et al., 2009; Adams et al., 2013a, 2013b].

\section{Models and Meteorological Analyses}

[22] GMI, MIMOSA, MERRA, and DMPs derived from MERRA can be used to trace the location and extent of the polar vortex. We use all of these to confirm the passage of polar vortex air over Toronto in this study.

\subsection{Potential Vorticity From MIMOSA and MERRA}

[23] We use PV maps centered over the North Pole to determine the location and extent of the polar vortex. PV is an excellent polar vortex tracer because the polar vortex is defined by the polar night jet, and as the vortex spins up in the autumn, PV increases and strong PV gradients form along the vortex edge [e.g., Nash et al., 1996]. PV is conserved on potential temperature surfaces and behaves similarly to a chemical tracer in the absence of diabatic and frictional effects [Hoskins et al., 1985].

[24] We have obtained PV maps from the MIMOSA model and the MERRA data reanalysis for this study. We have also extracted the MIMOSA and MERRA PV time series over TAO's coordinates to look for enhancements in potential vorticity that coincide with the enhancements in our stratospheric partial column measurements.

[25] MIMOSA is a high-resolution $\left(1^{\circ}\right.$ by $\left.1^{\circ}\right)$ advection model of PV developed at the Service d'Aéronomie (for a full description, see Hauchecorne et al. [2002]). MIMOSA is driven by the European Centre for MediumRange Weather Forecasts wind fields, which are advected along potential temperature surfaces (ether.ipsl.jussieu.fr/ ether/pubipsl/mimosa_uk.jsp). PV is given in potential vorticity units $\left(1 \mathrm{pvu}=10^{-6} \mathrm{~K} \mathrm{~m} \mathrm{mg}^{-1} \mathrm{~s}^{-1}\right)$. MIMOSA was developed to quantify the effect of transport of polar air on lower stratospheric ozone at midlatitudes [Marchand et al., 2003] and has been shown to be capable of predicting filament locations to within $100 \mathrm{~km}$ [Hauchecorne et al., 2002], making it well suited for this study.

[26] MERRA is a long-term meteorological data reanalysis using NASA's Global Modeling and Analysis Office Goddard Earth Observing System Version 5.2.0 (GEOS-5) data assimilation system. It was developed at the NASA Goddard Earth Sciences Data and Information Services Center [Rienecker et al., 2011]. The GEOS-5 system is run at a resolution of $0.5^{\circ}$ latitude by $0.67^{\circ}$ longitude, but $\mathrm{PV}$ for MERRA is output on a reduced resolution grid $\left(1^{\circ}\right.$ by $\left.1.25^{\circ}\right)$ and on pressure levels over which PV is not conserved. We interpolate MERRA PV onto potential temperature levels and compare PV at four vertical levels (435 K, $475 \mathrm{~K}$ $675 \mathrm{~K}$, and $950 \mathrm{~K}$ ) to that from MIMOSA. MERRA and MIMOSA maps agree well despite being based on different meteorological analyses, so the two autonomously confirm the location of the polar vortex and its filaments. MERRA output goes as far back as 1979 and has output every $3 \mathrm{~h}$ for each day (in section 4 we present MERRA output at 15 UT on each day, which coincides closely with morning measurements at TAO), whereas MIMOSA output is only available beginning in 2005 and only output at 12 UT on each day. Therefore, only the MERRA fields allow us to check for polar intrusion events in our data set between 2002 and 2004.

\section{2. $\mathrm{N}_{2} \mathrm{O}$ and $\mathrm{O}_{3}$ From GMI}

[27] Since the chemical lifetime of $\mathrm{N}_{2} \mathrm{O}$ in the stratosphere is much longer than dynamical time scales, we use modeled $\mathrm{N}_{2} \mathrm{O}$ from the GMI 3-D CTM [Strahan et al., 2007] as another polar vortex tracer. Because $\mathrm{N}_{2} \mathrm{O}$ is a passive tracer of air motions, it has been used in previous dynamical studies [e.g., Orsolini et al., 1998; Orsolini and Grant, 2000; Manney et al., 2000]. GMI O $\mathrm{G}_{3}$ is also used in this study as its chemical lifetime is long in the lower stratosphere in the absence of heterogeneous chemical $\mathrm{O}_{3}$ depletion. In section 4, we present $\mathrm{GMI} \mathrm{O}_{3}$ maps in order to both track the location of the polar vortex and assess whether polar $\mathrm{O}_{3}$ is reduced or enhanced at the time of our events.

[28] GMI includes both tropospheric and stratospheric chemistry and is driven by assimilated meteorological fields from MERRA [Rienecker et al., 2011]. Combined stratosphere-troposphere runs [Duncan et al., 2007] were used in this study, and natural and anthropogenic emissions were both considered. The horizontal resolution of the model is $2^{\circ} \times 2.5^{\circ}$, output on 72 pressure levels, with a lid at $0.015 \mathrm{hPa}(\sim 75 \mathrm{~km})$. We present polar maps interpolated onto four potential temperature surfaces $(435 \mathrm{~K}, 475 \mathrm{~K}$, $675 \mathrm{~K}$, and $950 \mathrm{~K}$ ) that were produced from the output at 12-12:30 UT.

\subsection{Derived Meteorological Products}

[29] Schoeberl and Newman [1995] have shown that the vertical extent of polar vortex filaments varies greatly. 


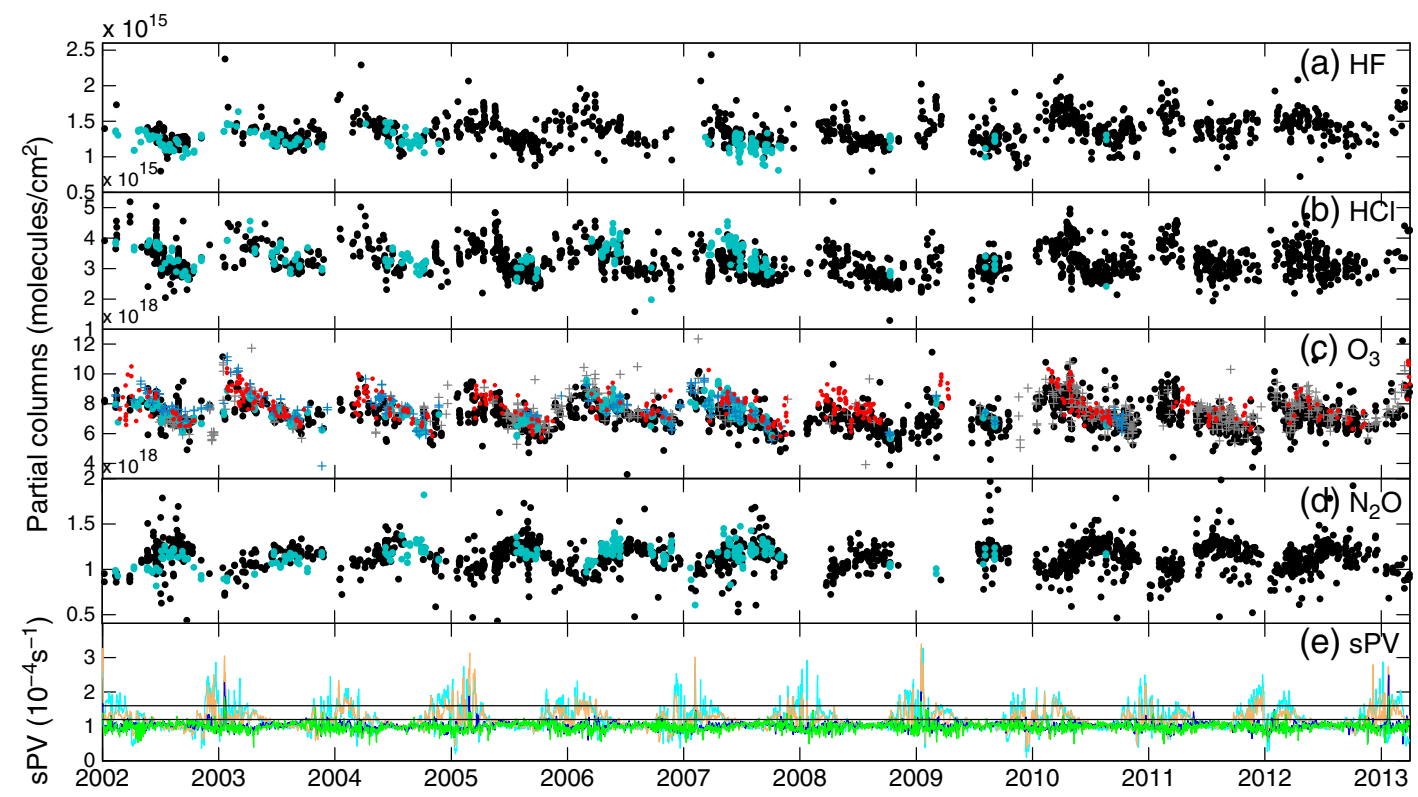

Figure 2. TAO (black), CARE (cyan), and OSIRIS (red) stratospheric partial columns (12-50 km) of (a) $\mathrm{HF}$, (b) $\mathrm{HCl}$, (c) $\mathrm{O}_{3}$ (from the $3051 \mathrm{~cm}^{-1}$ microwindow), and (d) $\mathrm{N}_{2} \mathrm{O}$. In the Figure $2 \mathrm{c}$, the grey and blue crosses are retrievals from the $1000 \mathrm{~cm}^{-1}$ microwindow for TAO and CARE, respectively. Figure $2 \mathrm{e}$ is scaled potential vorticity over Toronto at $435 \mathrm{~K}$ (green), $475 \mathrm{~K}$ (blue), $675 \mathrm{~K}$ (orange), and $950 \mathrm{~K}$ (cyan), and the inner $\left(\mathrm{sPV}=1.6 \times 10^{-4} \mathrm{~s}^{-1}\right)$ and outer $\left(\mathrm{sPV}=1.2 \times 10^{-4} \mathrm{~s}^{-1}\right)$ vortex edges are indicated by the upper and lower horizontal lines, respectively.

Typically, filaments are shallow (a few kilometers thick), but sometimes they can extend through much of the depth of the stratosphere. In order to determine the vertical extent of our observed polar vortex intrusions, we use DMPs [Manney et al., 2007] based on MERRA meteorological fields, which include temperature, potential temperature, pressure, equivalent latitude (EqL), PV, scaled PV (given in vorticity units $\left(10^{-4} \mathrm{~s}^{-1}\right)$, tropopause height, horizontal winds, and vortex edge location, all interpolated to the measurement locations. Equivalent latitude is the latitude that would enclose the same area between it and the pole as a given PV contour [Butchart and Remsberg, 1986; Manney et al., 2007]. The vortex edge is defined as in Manney et al. [2007] by the EqL of the maximum of the wind speed times the PV gradient. Scaled PV (sPV) is PV divided by $\delta \theta / \delta \mathrm{p}$, such that $\mathrm{sPV}$ is normalized at all vertical levels in the stratosphere [Dunkerton and Delisi, 1986; Manney et al., 1994].

[30] We use the time series of MERRA sPV over Toronto at four stratospheric levels (same as above), and we also examine the vertical profiles of sPV over Toronto during the polar intrusion events to determine the vertical extent over which the polar intrusions occurred. SPV is used to determine when Toronto is inside the polar vortex; the outer edge of the vortex is defined to be at an sPV of $1.2 \times 10^{-4} \mathrm{~s}^{-1}$, and the inner vortex edge is defined to be at an sPV of $1.6 \times 10^{-4} \mathrm{~s}^{-1}$ [Manney et al., 2007]. Note that except during vortex breakup, the EqL and sPV methods of determining the vortex edge location agree quite well in the lower stratosphere (which comprises the bulk of the $\mathrm{O}_{3}$ column) but that no automated vortex edge identification works especially well in the springtime [Manney et al., 2007].

\section{Results and Discussion}

\subsection{Identification and Frequency of Polar Intrusion Events}

[31] The complete TAO and CARE time series, from January 2002 until March 2013, of individual measurements of stratospheric $\mathrm{HF}, \mathrm{HCl}, \mathrm{O}_{3}$, and $\mathrm{N}_{2} \mathrm{O}$ partial columns are shown in Figure 2. These gases have seasonal cycles, with $\mathrm{HF}, \mathrm{HCl}$, and $\mathrm{O}_{3}$ stratospheric columns having maxima in the spring and $\mathrm{N}_{2} \mathrm{O}$ stratospheric columns anticorrelated, having maxima in the late summer/early fall. There are also many outliers in the time series (Figure 2) that are associated with good spectral fits and realistic retrieved profiles, and so we would like to determine the causes of some of this atmospheric variability. OSIRIS $\mathrm{O}_{3}$ partial columns $(12-50 \mathrm{~km}$ ) over Toronto (within $600 \mathrm{~km}$ ) are included to help fill in the gaps in the FTIR time series, and they agree well with the TAO DA8 $\mathrm{O}_{3}$ measurements, with only a $5 \%$ systematic bias (OSIRIS greater than TAO). Therefore, there is a good connection between the ground-based measurements and the OSIRIS maps that appear in section 4.3. Figure 2 also includes the sPV time series at four vertical levels in the stratosphere: $435 \mathrm{~K}(\sim 16 \mathrm{~km}), 475 \mathrm{~K}(\sim 18 \mathrm{~km})$, $675 \mathrm{~K}(\sim 25 \mathrm{~km})$, and $950 \mathrm{~K}(\sim 32 \mathrm{~km})$, and the two horizontal lines indicate the boundary of the outer vortex edge $\left(\right.$ at $\left.\mathrm{sPV}=1.2 \times 10^{-4} \mathrm{~s}^{-1}\right)$, and the inner vortex edge (at $\mathrm{sPV}=$ $\left.1.6 \times 10^{-4} \mathrm{~s}^{-1}\right)$. Note that there are more polar intrusions over Toronto in the upper stratosphere $(650 \mathrm{~K}$ and $950 \mathrm{~K})$ because the polar vortex is typically larger, and filaments tend to tilt away from the pole at higher altitudes [Schoeberl and Newman, 1995].

[32] To identify polar intrusion events, we started with the SPV definition of inner and outer vortex edge, and the 


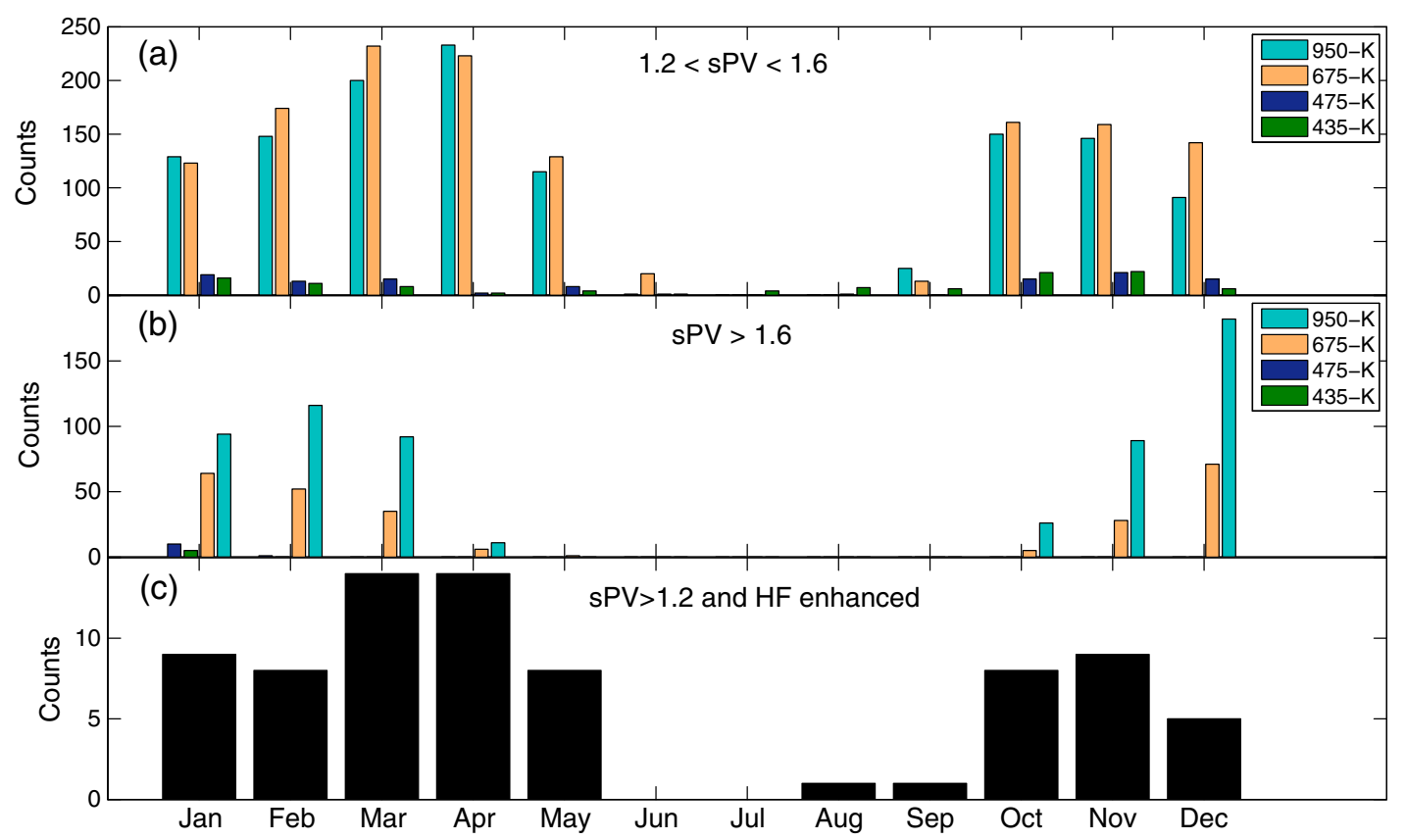

Figure 3. Number of polar intrusion days at four vertical levels $(950 \mathrm{~K}, 675 \mathrm{~K}, 475 \mathrm{~K}$, and $435 \mathrm{~K})$ over Toronto from January 2002 to March 2013, from the MERRA DMPs, separated by month. sPV is given in $10^{-4} \mathrm{~s}^{-1}$. (a) The number of intrusions that are within the vortex edge region, (b) the number of intrusions that are within the vortex, and (c) the number of intrusion days that met the four criteria described in section 4.1 .

sPV time series over Toronto from the DMPs. Scaled PV on the four levels suggests that between January 2002 and March 2013, there were 675 days (16\% of days) when the polar vortex $\left(\mathrm{sPV}>1.6 \times 10^{-4} \mathrm{~s}^{-1}\right)$ passed over Toronto and 1492 days ( $36 \%$ of days) when the edge of the polar vortex $\left(1.2 \times 10^{-4} \mathrm{~s}^{-1}<\mathrm{sPV}<1.6 \times 10^{-4} \mathrm{~s}^{-1}\right)$ was over Toronto. Figures $3 \mathrm{a}$ and $3 \mathrm{~b}$ show these days distributed by month, and Figures $4 \mathrm{a}$ and $4 \mathrm{~b}$ show these days distributed by year.
Since the FTIR spectrometer cannot measure on cloudy days and has sporadic downtime for maintenance and repairs, the gaps in our data set make it certain that we are not detecting all of these polar intrusion events over southern Ontario. In fact, there are FTIR measurements at TAO on only $\sim 14 \%$ of those "enhanced sPV" $\left(>1.2 \times 10^{-4} \mathrm{~s}^{-1}\right)$ days. However, while the FTIR data set is missing $86 \%$ of the polar intrusions (in enhanced sPV), our subset of measurement days

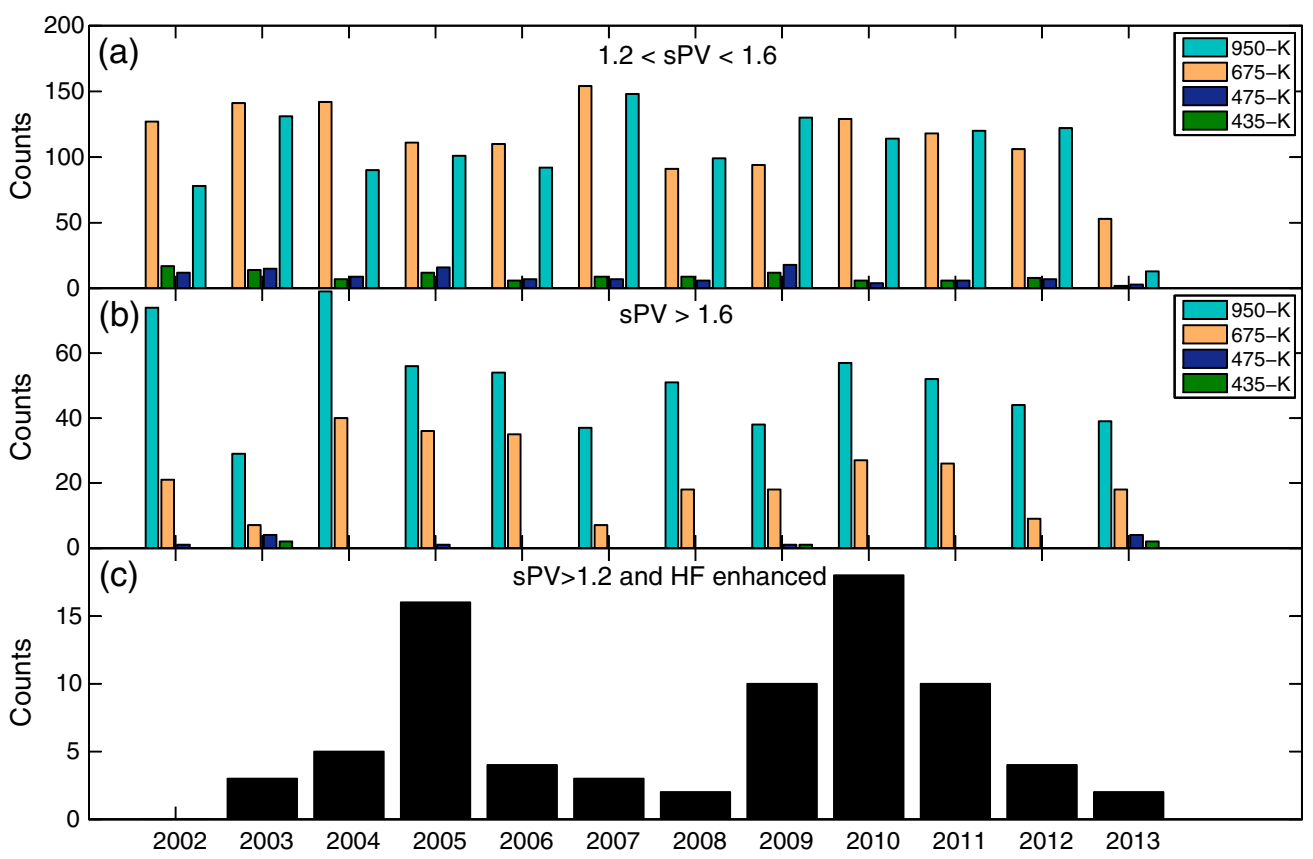

Figure 4. Same as Figure 3 but separated by year. 

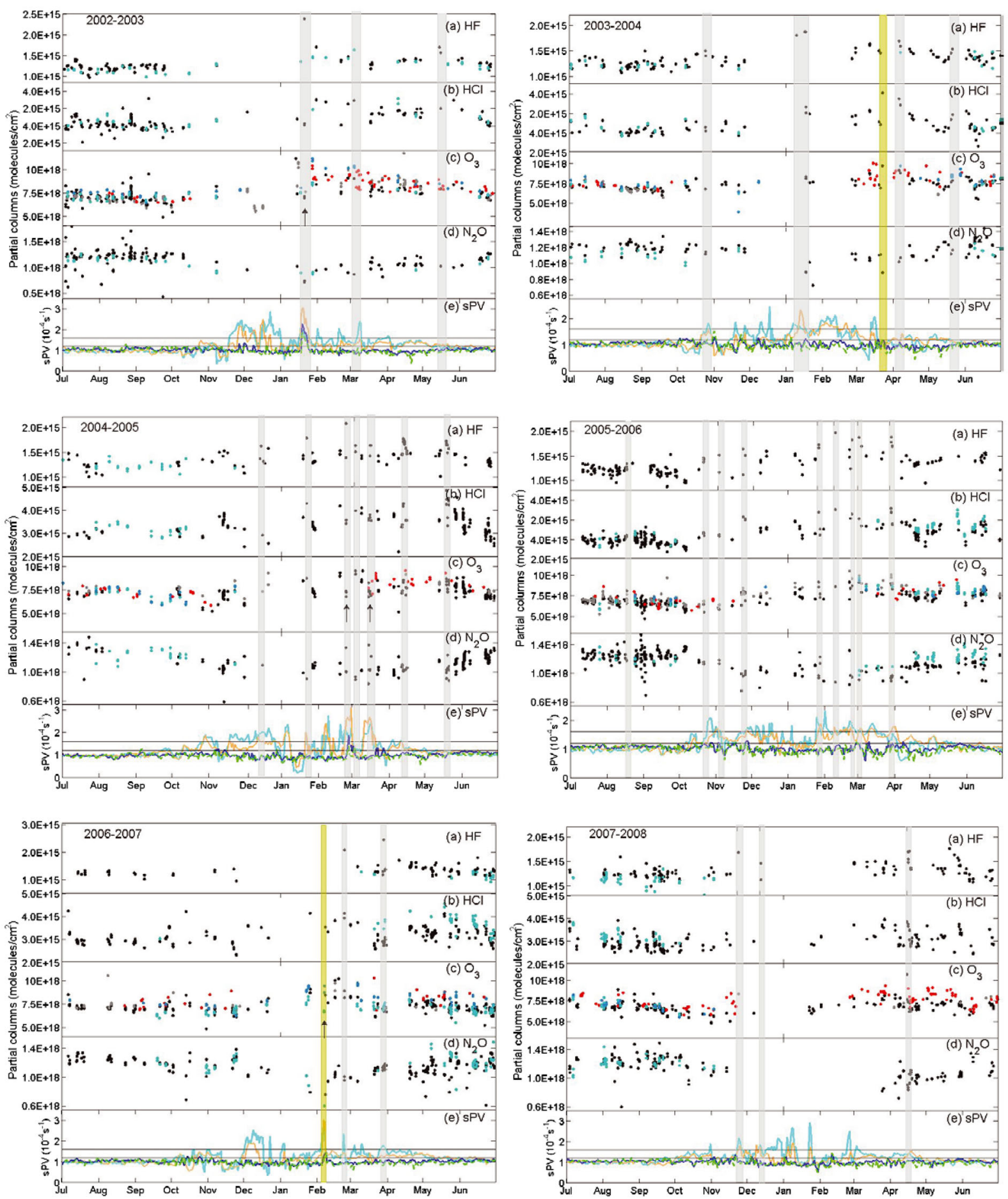

Figure 5. Same as Figure 2 but an expanded view of each year, and 3051 and $1000 \mathrm{O}_{3}$ products are combined into black (TAO) and cyan (CARE) points. The total errors on these partial columns are $3 \%$ for $\mathrm{HF}, 3.5 \%$ for $\mathrm{HCl}, 7.5 \%$ for $12-23 \mathrm{~km} \mathrm{O}_{3}, 11.6 \%$ for $23-50 \mathrm{~km} \mathrm{O}_{3}$, and $9 \%$ for $\mathrm{N}_{2} \mathrm{O}$. Grey and yellow boxes highlight the polar intrusion events (grey showing events that met the four criteria and yellow showing events that met only three of the four criteria).

gets a similar percentage with polar intrusions to that found with the sPV time series.

[33] Since HF is a good dynamical tracer, we expect polar vortex intrusions to cause variability in the FTIR time series (though to a lesser extent if the polar intrusion is shallow and/or much higher than $35 \mathrm{~km}$ where it is not contributing a large amount to the column). Therefore, we looked at (1) the HF stratospheric columns that were enhanced, defined as when the HF stratospheric column was more than $1 \sigma$ greater than the monthly mean (in either the singular monthly mean or the climatological (2002-2013) monthly mean). We flagged those days as "enhanced HF" days. Then we 

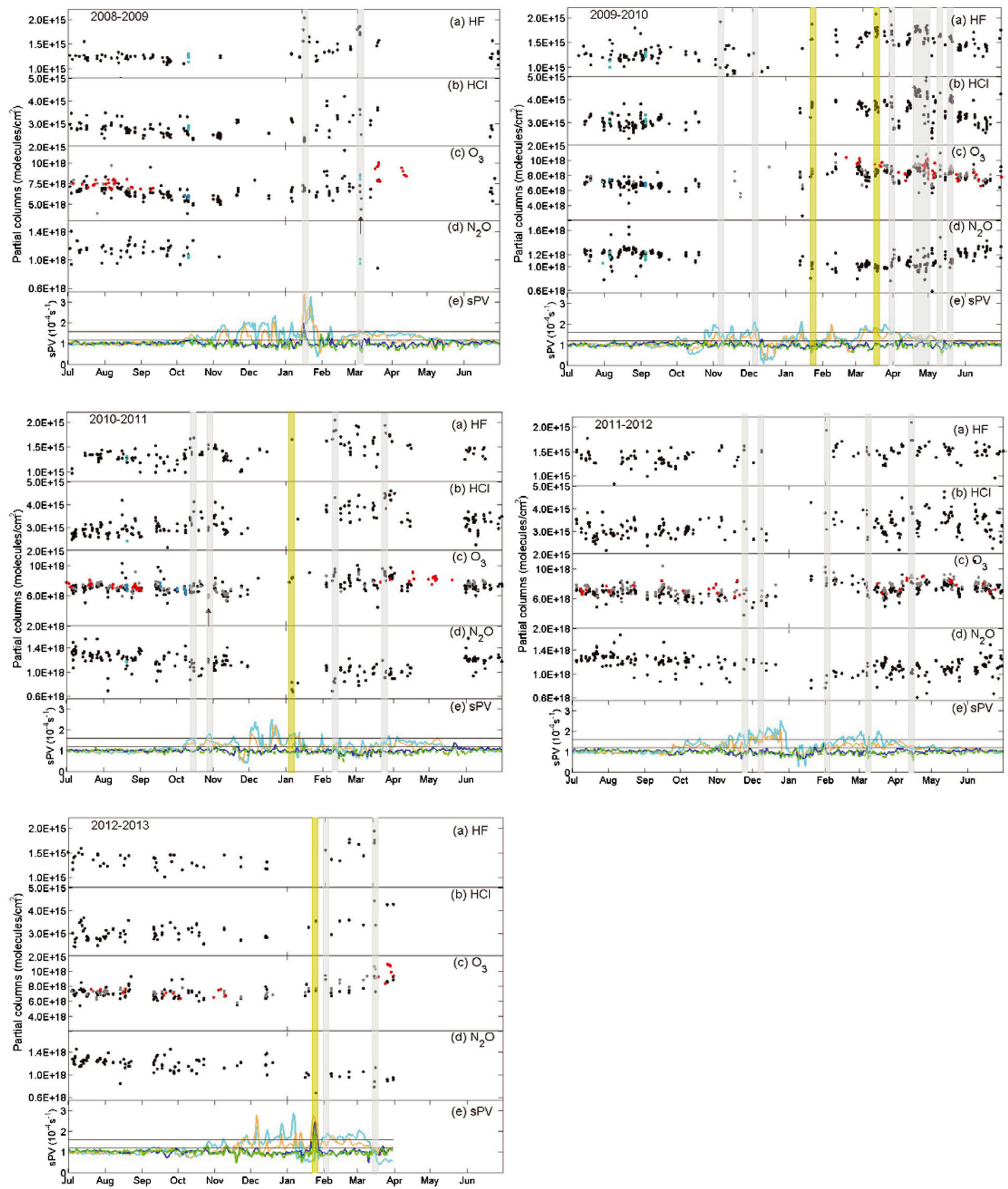

Figure 6. Same as Figure 6 but later years.

determined whether these flagged days also had (2) reduced $\mathrm{N}_{2} \mathrm{O}$ stratospheric columns (compared to a few days before and after the event), and (3) $\mathrm{sPV}>1.2 \times 10^{-4} \mathrm{~s}^{-1}$. Finally, (4) we checked the MIMOSA and MERRA PV maps at the four vertical levels in the stratosphere mentioned above to see if there was a vortex excursion or filament over Toronto on those dates. Using these four criteria, we found 47 polar vortex intrusions. Six additional polar intrusions were found that did not quite satisfy all of the criteria. Either there were not enough HF measurements to make the $1 \sigma$ statistic meaningful (but the HF column was increased, and sPV was $>1.2 \times 10^{-4} \mathrm{~s}^{-1}$ ) or the $\mathrm{sPV}$ value was just below $1.2 \times$ $10^{-4} \mathrm{~s}^{-1}$ (but the HF column was enhanced and the polar map confirms a filament). Nevertheless, we include those six in our study for a total of 53 "polar intrusion events," on which we focus the rest of our discussion. There were an average of four events detected in the FTIR time series per year. Between November and April inclusive ("winter/spring"), the polar intrusion events consist of $16 \%$ of our measurements. 
Table 2. Percent Increase in 2003-2012 Stratospheric Column Variability and sPV Variability Over Toronto Due To Polar Intrusion Events ${ }^{\mathrm{a}}$

\begin{tabular}{lc}
\hline Species & $\begin{array}{c}\text { Mean Increase in } \\
\text { Variability }(2003-2012)\end{array}$ \\
\hline $\mathrm{HF}(12-50 \mathrm{~km})$ & $15.1 \%$ \\
$\mathrm{HCl}(12-50 \mathrm{~km})$ & $7.1 \%$ \\
$\mathrm{~N}_{2} \mathrm{O}(12-50 \mathrm{~km})$ & $1.7 \%$ \\
$\mathrm{O}_{3}(12-50 \mathrm{~km})$ & $5.7 \%$ \\
$\mathrm{O}_{3}(12-23 \mathrm{~km})$ & $3.8 \%$ \\
$\mathrm{O}_{3}(23-50 \mathrm{~km})$ & $-0.5 \%$ \\
$\mathrm{sPV} 435 \mathrm{~K}$ & $4.4 \%$ \\
$\mathrm{sPV} 475 \mathrm{~K}$ & $11.2 \%$ \\
$\mathrm{sPV} 675 \mathrm{~K}$ & $14.5 \%$ \\
$\mathrm{sPV} 950 \mathrm{~K}$ & $5.2 \%$ \\
$\mathrm{sPV} 435 \mathrm{~K}$ & $9.3 \%$ \\
$\mathrm{sPV} 475 \mathrm{~K}$ & $14.4 \%$ \\
$\mathrm{sPV} 675 \mathrm{~K}$ & $58.8 \%$ \\
sPV $950 \mathrm{~K}$ & $62.0 \%$ \\
\hline
\end{tabular}

${ }^{\mathrm{a}} \mathrm{O}_{3}$ products are from the 1000 and 3051 microwindows combined. The first set of sPV variability is due to 53 polar intrusion events on SPV during the FTIR measurement days. The second set of sPV variability is due to all polar intrusion days in the SPV time series not constrained by HF measurement days.

[34] The monthly and yearly distribution of these 53 polar intrusion events are shown in Figures $3 \mathrm{c}$ and 4(c), respectively. Note that the monthly distribution is similar to the enhanced sPV distribution, with the differences being due to the measurement sampling bias. It turned out that all of the $\mathrm{HF}$ enhancements in December through March were during polar vortex intrusions. The HF enhancements in April, May, October, and November were rarely coinciding with a polar vortex intrusion, and only one enhancement in the summer (August 2005) was during a polar intrusion event. This suggests that the December to March variability in the HF time series is due to polar vortex air passing over Toronto. The late spring, summer, and fall variability in HF must be due to other causes, and this variability (in May through September) is about half that during the winter (see section 4.2 for more discussion on HF variability).

[35] Note that no one criterion for $H F$ enhancements (e.g., $1 \sigma$, median absolute deviation, and absolute cutoff) captured all of the polar intrusion events so there could be more intrusions in the FTIR data set that were missed. Also the DMPs (and hence SPV) are interpolated values; therefore, a slight mismatch in the location of the filament between MERRA and the "truth" could make the difference between considering something inside or outside the vortex [Fairlie et al., 1997; Manney et al., 1998]-hence the six additional days.

\subsection{Effect on Trace Gases: Variability}

[36] All of the polar intrusion events we found in the measurements are highlighted by the grey (met all four criteria) and yellow (met three out of four criteria) boxes in Figures 5 and 6 . These figures show the time series expanded for each year.

[37] The variability introduced in the FTIR time series by the polar intrusion events (Var) for each trace gas in the complete time series is calculated for each year and for the complete time series, with the latter given in Table 2 . This table shows the percent differences between the standard deviations calculated from our FTIR measurements with $\left(\sigma_{\text {with }}\right)$ and without $\left(\sigma_{\text {wout }}\right)$, the polar intrusion events:

$$
\operatorname{Var}=\frac{\sigma_{\text {with }}-\sigma_{\text {wout }}}{\sigma_{\text {with }}} \times 100 \% .
$$

The upper stratospheric $\mathrm{O}_{3}$ value in Table 2 is negative; this means that the polar intrusion events decreased the variability in the time series. The magnitude of the negative value is small $(<-0.5 \%)$, which may just be interpreted as a negligible effect on the time series variability. However, $\mathrm{O}_{3}$ variability can be reduced by the following scenarios: (i) the polar vortex filament may have a similar amount of $\mathrm{O}_{3}$ to that in unperturbed midlatitude air or (ii) a springtime polar vortex filament may have $\mathrm{O}_{3}$-poor air, making the column more like the summertime $\mathrm{O}_{3}$ columns (when there is a seasonal minimum and more FTIR measurements).

[38] From 2003 to 2012, polar intrusion events cause a mean increase in variability of $15.1 \%, 7.1 \%$, and $5.7 \%$ for stratospheric $\mathrm{HF}, \mathrm{HCl}$, and $\mathrm{O}_{3}$, respectively. We left out 2002 and 2013 from our calculations because early 2002 was before regular daily measurements commenced at TAO, and therefore, there were very few measurements during January to April 2002, and the 2013 data set is not yet complete.

[39] The variability introduced by the polar vortex intrusions is greatest for HF, consistent with it being a good dynamical tracer. For example, in January 2003, we have one of the highest outliers in the HF (and $\mathrm{N}_{2} \mathrm{O}$ ) columns (Figure 5), which occurred when the polar vortex was over Toronto for the largest altitude range (see mauve line in Figure 12). In this year, the polar intrusions caused a $35 \%$ increase in $\mathrm{HF}$ variability. The variability of $\mathrm{HCl}$ is less sensitive to the polar vortex intrusions in most years, likely because dynamical enhancements of $\mathrm{HCl}$ can be offset by chemical processing. However, $\mathrm{HCl}$ is still significantly affected by polar vortex air, consistent with Coffey et al. [2008]. The polar vortex intrusions have a smaller effect on the variability of $\mathrm{O}_{3}$ because the amount of $\mathrm{O}_{3}$ in the filaments is not consistently greater than (like $\mathrm{HF}$ and $\mathrm{HCl}$ ) or less than (like $\mathrm{N}_{2} \mathrm{O}$ ) that in midlatitude air. The amount of $\mathrm{O}_{3}$ in a filament is influenced by the altitude range at which it occurs, the dynamics of the polar vortex system, and chemical processing. Finally, the small effect on $\mathrm{N}_{2} \mathrm{O}$ variability is likely due to the smaller altitude range that contributes to the $\mathrm{N}_{2} \mathrm{O}$ stratospheric column (see end of section 2.1.1). Therefore, only lower stratospheric polar intrusions would have a significant effect on the $\mathrm{N}_{2} \mathrm{O}$ time series.

[40] Figure 7 shows the variability (given by the standard deviation from the climatological monthly mean) of each species for the complete time series (black circles) and the time series without the polar intrusion events (red crosses). In addition to Table 2, this figure shows that the largest effect on variability occurs for $\mathrm{HF}$, during the winter and early spring months. Figure 7 illustrates that there is about twice as much variability in the HF time series in the winter as there is in the summer and that about half of the increase of the winter variability compared to summer is due to the polar intrusion events.

[41] The variability in sPV at four different levels $(435 \mathrm{~K}$, $475 \mathrm{~K}, 675 \mathrm{~K}$, and $950 \mathrm{~K}$ ) was also calculated and included in Table 2 and Figure 7. The first set of sPV values in Table 2 are results when we only consider the 53 events and their effect on sPV during the FTIR measurement days. The 


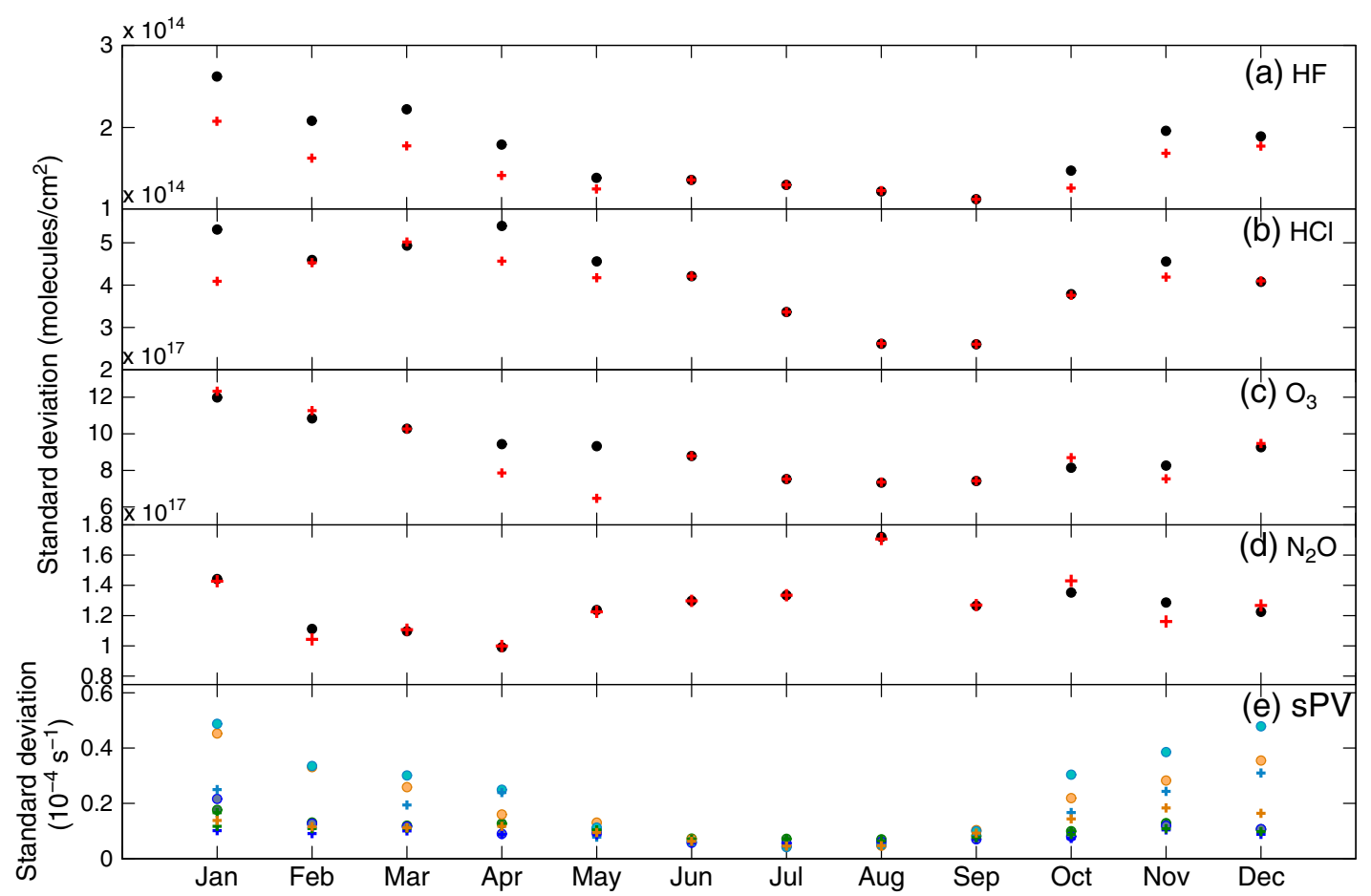

Figure 7. Variance in TAO stratospheric partial columns of (a) $\mathrm{HF}$, (b) $\mathrm{HCl}$, (c) $\mathrm{O}_{3}$, (d) $\mathrm{N}_{2} \mathrm{O}$, and in (e) $\mathrm{sPV}$, as given by the standard deviation from the climatological monthly mean for each month. Circles are for the full time series, and crosses are for the time series without the polar intrusion events. In Figure 7e, $435 \mathrm{~K}$ is green, $475 \mathrm{~K}$ is blue, $675 \mathrm{~K}$ is orange, and $950 \mathrm{~K}$ is cyan, and the crosses are for the time series without the enhanced sPV days.

second set of SPV values are the results if we are not constrained to FTIR measurement days and consider the full sPV time series during which there are a total of 2167 polar intrusion days from January 2002 to March 2013. When all of these are taken into account, their effect on sPV variability is $9.3 \%, 14.4 \%, 58.8 \%$, and $62.0 \%$ at $435 \mathrm{~K}, 475 \mathrm{~K}, 675 \mathrm{~K}$, and $950 \mathrm{~K}$, respectively, and Figure 7 shows this effect by month (with circles showing the variability on the full SPV time series and crosses showing the variability on the sPV time series without the enhanced sPV days). Note that the monthly HF variability with and without polar intrusion events follows a very similar shape to the sPV variability (Figures 7a and 7e), which supports the use of FTIR HF columns to detect polar vortex intrusions.

\subsubsection{Effect on $\mathrm{O}_{3}$ Columns}

[42] Generally speaking, stratospheric $\mathrm{O}_{3}$ columns above Toronto are slightly greater during the polar intrusion events, consistently agreeing with the GMI model, the Microwave Limb Sounder (MLS) on the Earth Observing System Aura satellite, the Earth Probe/Total Ozone Mapping
Spectrometer (EP/TOMS), the Ozone Monitoring Instrument (OMI), and OSIRIS $\mathrm{O}_{3}$ measurements. The $\mathrm{O}_{3}$ stratospheric columns can be split into $12-23 \mathrm{~km}$ and $23-50 \mathrm{~km}$, as these partial columns have at least 1 DOFS each. Though not shown in Figures 5 and 6, these lower and upper stratospheric partial columns provide more insight into which region of the stratosphere any changes to the $\mathrm{O}_{3}$ column are occurring. The total errors on these partial columns are $7.5 \%(12-23 \mathrm{~km})$ and $11.6 \%(23-50 \mathrm{~km})$ for the 3051 microwindow and 9.0\% (12-23 km) and 5.7\% (23-50 km) for the 1000 microwindow. When only random errors are considered, they are $2.6 \%(12-23 \mathrm{~km})$ and $2.3 \%(23-50 \mathrm{~km})$ for the 3051 microwindow and $2.0 \%(12-23 \mathrm{~km})$ and $2.1 \%$ $(23-50 \mathrm{~km})$ for the 1000 microwindow.

[43] In 2005, 2010, and the total time series, there were significant (greater than the standard error in the $\mathrm{O}_{3}$ partial columns) changes in the average of our stratospheric $\mathrm{O}_{3}$ columns due to the polar intrusion events. The only significant decreases in annual stratospheric $\mathrm{O}_{3}$ columns due to the polar intrusion events were in the $23-50 \mathrm{~km}$ partial

Table 3. Percent Change in Stratospheric Columns of $\mathrm{O}_{3}$ Over Toronto Due To Polar Intrusion Events for the Given Year and for the Total Time Series (2002 to 2013) ${ }^{\mathrm{a}}$

\begin{tabular}{|c|c|c|c|c|c|c|c|c|c|c|c|}
\hline $\begin{array}{l}\text { Partial } \\
\text { Column }\end{array}$ & 2003 & 2004 & 2005 & 2006 & 2007 & 2008 & 2009 & 2010 & 2011 & 2012 & $\begin{array}{l}\text { Total (2003- } \\
\text { 2012) mean }\end{array}$ \\
\hline $12-50 \mathrm{~km}$ & $-1.3 \%$ & $2.3 \%$ & $2.1 \%$ & $4.2 \%$ & $0.3 \%$ & $1.4 \%$ & $0.3 \%$ & $15.3 \%$ & $-3.3 \%$ & $5.1 \%$ & $4.5 \%$ \\
\hline $12-23 \mathrm{~km}$ & $1.0 \%$ & $2.9 \%$ & $7.3 \%$ & $5.7 \%$ & $0.0 \%$ & $1.5 \%$ & $5.8 \%$ & $14.9 \%$ & $-1.2 \%$ & $3.3 \%$ & $4.8 \%$ \\
\hline $23-50 \mathrm{~km}$ & $-4.2 \%$ & $-0.5 \%$ & $-7.0 \%$ & $-1.4 \%$ & $0.4 \%$ & $-0.1 \%$ & $-6.5 \%$ & $-2.9 \%$ & $-2.1 \%$ & $1.3 \%$ & $-0.9 \%$ \\
\hline
\end{tabular}

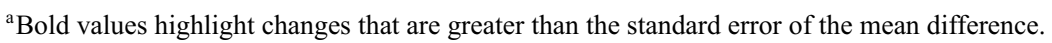



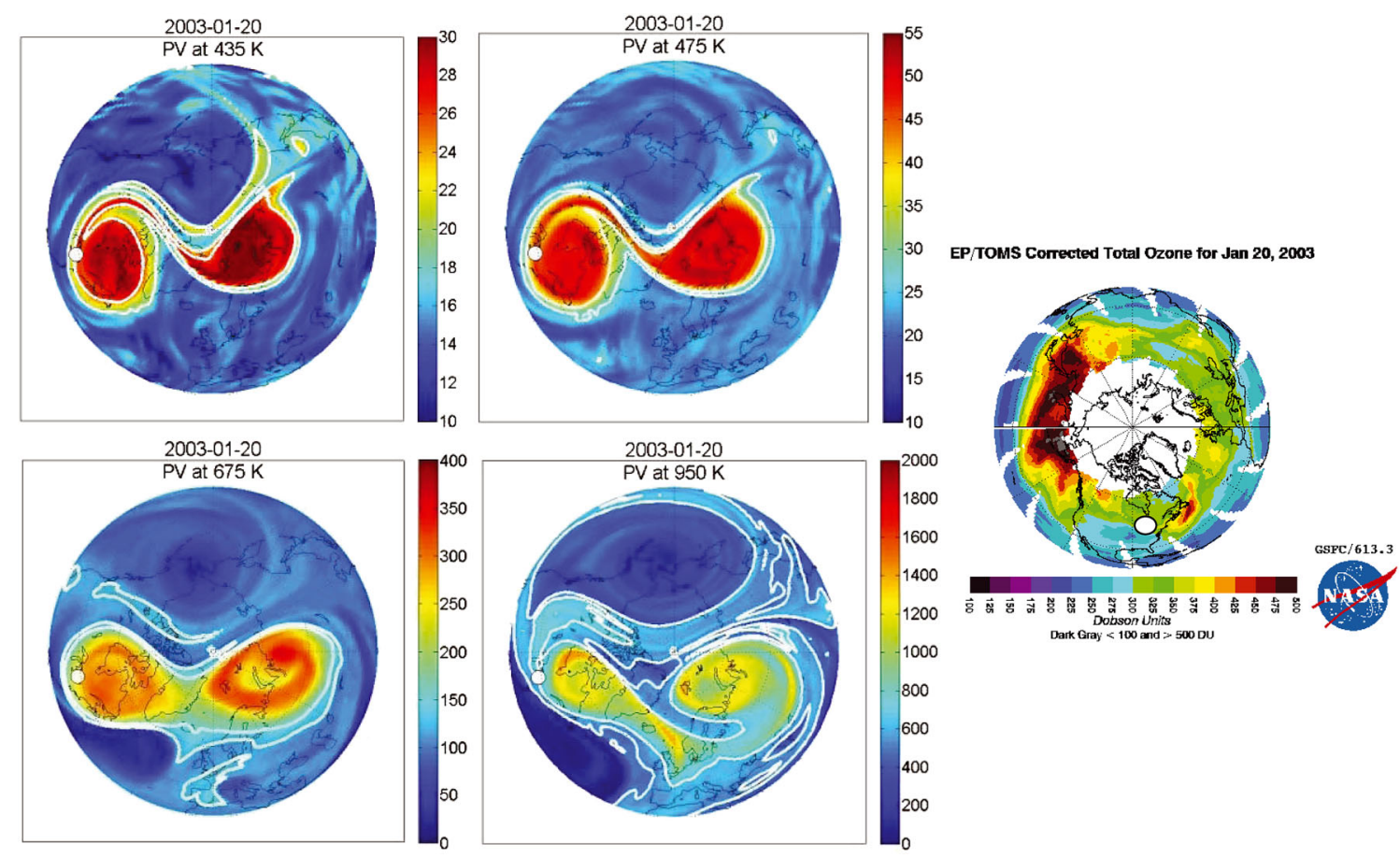

Figure 8. Polar intrusion event on 20 January 2003. MERRA PV (in pvu) at $435 \mathrm{~K}, 475 \mathrm{~K}, 675 \mathrm{~K}$, and $950 \mathrm{~K}$. The EP TOMS total $\mathrm{O}_{3}$ column map is also shown (note that this map is oriented $90^{\circ}$ counterclockwise compared to the MERRA maps). White circles on each map represents the location of Toronto/Egbert. White contours denote the inner and outer vortex edge limits.

columns in 2003, 2005, and 2009. These changes in $\mathrm{O}_{3}$ are summarized in Table 3 and were calculated using

$$
\text { Change }=\frac{\overline{O_{3 \text { with }}}-\overline{O_{3 \text { wout }}}}{\overline{O_{3 \text { with }}}} \times 100 \% \text {, }
$$

where $\overline{O_{3 \text { with }}}$ and $\overline{O_{3 \text { wout }}}$ are the means of the stratospheric $\mathrm{O}_{3}$ partial columns for a given year, with and without the polar intrusion events, respectively. The bold values in Table 3 indicate that the changes in $\mathrm{O}_{3}$ are greater than the standard error on $\overline{O_{3 \text { with }}}$. However, since our FTIR measurements are neither frequent nor uniform in time, these statistics apply only to our data set and should not be interpreted as representing the increase/decrease in $\mathrm{O}_{3}$ over the Toronto region that would be observed in a continuous data set.

\subsection{Effect on Trace Gases: Case Studies}

[44] As mentioned in section 4.1, polar PV maps from MERRA and MIMOSA (when available) were used to verify structures extending from the polar vortex southward over the Toronto region. Figures 8 to 11 present these maps for four sample polar intrusion events at the vertical levels at which the intrusion occurred. In these maps, Toronto's location is marked by a white circle, and two white contours indicate the inner and outer vortex edges (equivalent to the horizontal black lines in Figures 2, 5, and 6). In Figures 9 to 11 , the shape of the polar vortex and its filaments given by MERRA PV were confirmed with the MIMOSA PV maps (for which the magnitudes of PV are also similar) and modeled $\mathrm{N}_{2} \mathrm{O}$ from GMI. Also from GMI is modeled $\mathrm{O}_{3}$, which will be discussed below.

[45] For all 53 polar intrusion events, the VMR of $\mathrm{N}_{2} \mathrm{O}$ given by GMI is much lower inside the polar vortex and filaments compared to midlatitudes as discussed in section 1 (see Figures 9 to 10 for four examples). Recall that GMI is driven by MERRA meteorological fields; therefore, we would expect the GMI maps to agree well with MERRA PV maps, which is why we also include MIMOSA PV in this study as a more independent check on the location of the polar vortex and its filaments.

[46] Section 4.3.1 discusses the impact of polar intrusions on Toronto area $\mathrm{O}_{3}$ using three case studies. The first two (January 2003 and February 2007) are examples of when polar $\mathrm{O}_{3}$ depletion caused a reduction in stratospheric $\mathrm{O}_{3}$ over Toronto, and the third (March 2011) is an example of when polar $\mathrm{O}_{3}$ depletion did not have an effect on Toronto stratospheric $\mathrm{O}_{3}$. Section 4.3.2 discusses an example of stratospheric warming causing the polar vortex to split apart.

\subsubsection{Impact on $\mathrm{O}_{3}$}

[47] Unlike some previous studies that focus on reduced $\mathrm{O}_{3}$ at midlatitudes [Marchand et al., 2003; Millard et al., 2003; Konopka et al., 2003; Keckhut et al., 2007], we find that the majority of the polar intrusion events identified over Toronto resulted in either a small increase or a negligible change in the $\mathrm{O}_{3}$ stratospheric columns (consistent with Newman et al. [1996], Orsolini et al. [2001], Godin et al. [2002], and Hauchecorne et al. [2002]). Marchand et al. [2003] modeled the effect of chemically depleted polar vortex air on northern midlatitudes with MIMOSA-CHIM (MIMOSA with chemistry) and reported that midlatitude $\mathrm{O}_{3}$ VMRs became increasingly affected by the polar vortex starting from around March (when it was responsible for $15 \%$ of diminished $\mathrm{O}_{3}$ at $475 \mathrm{~K}$ from $45^{\circ}-55^{\circ} \mathrm{N}$ ), reaching a maximum in April (when it was responsible for $50 \%$ of the diminished $\mathrm{O}_{3}$ at $475 \mathrm{~K}$ from $45^{\circ}-55^{\circ} \mathrm{N}$ ). Since the 

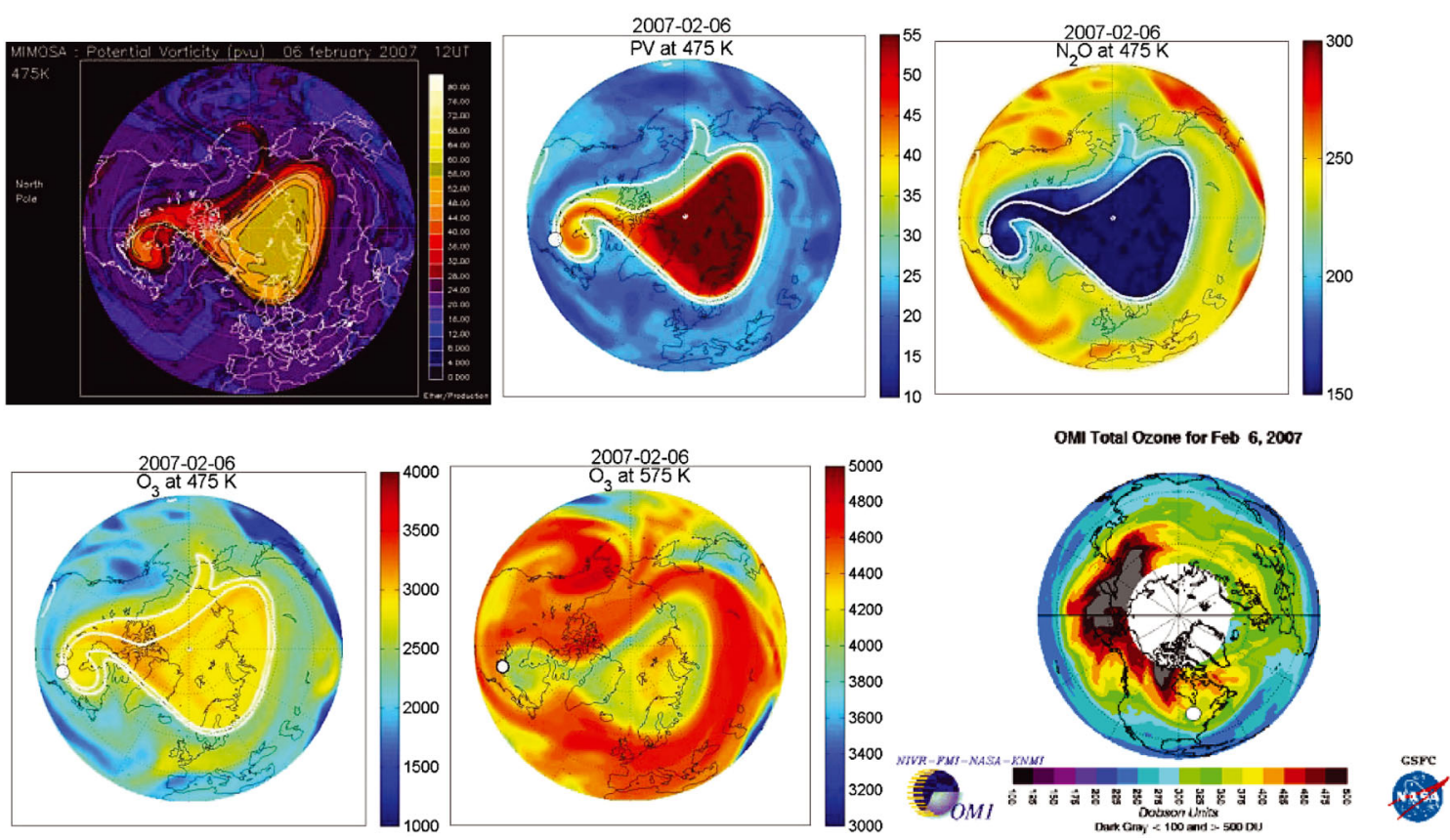

Figure 9. Polar intrusion event on 6 February 2007. (top) MIMOSA PV, MERRA PV (both in pvu), and GMI $\mathrm{N}_{2} \mathrm{O}$ (in ppbv). (bottom) $\mathrm{GMI} \mathrm{O}_{3}$ at $475 \mathrm{~K}$ and $575 \mathrm{~K}$ (both in ppbv) and $\mathrm{OMI}$ total column $\mathrm{O}_{3}$ (note that the OMI map is oriented $90^{\circ}$ counterclockwise compared to the other maps). White circles denote the location of Toronto/Egbert. White contours denote the inner and outer vortex edge limits.

Toronto region is located just south of their reported latitude band and most of our polar intrusion events occurred in March or before, we would expect polar intrusions to have less of an effect on our $\mathrm{O}_{3}$ columns. Marchand et al. [2003] also reported negligible $\mathrm{O}_{3}$ reductions in the filament structures (rather than vortex excursions). Since most of our events were filaments, our findings are consistent with the Marchand et al. [2003] study, as reduced $\mathrm{O}_{3}$ columns were rarely measured as a result of a filament over Toronto.

[48] We only found reduced $\mathrm{O}_{3}$ columns during six of the 53 polar intrusion events: on 20 January 2003, 23 February 2005, 15-16 March 2005 (both 2005 events supported by Rösevall et al. [2008]), 6 February 2007, 3-4 March 2009, and 27 October 2010 (see arrows in Figures 5 and 6). The lower (12-23 km) and upper (23-50 km) stratospheric columns were affected differently during these six events, with about half having a drop in the lower stratospheric partial column and little change in the upper stratospheric partial column, and the other half having a drop in the upper stratospheric partial column and little change in the lower stratospheric partial column. Two of these events are discussed in more detail below.

[49] On 20 January 2003, we have FTIR observations of reduced $\mathrm{O}_{3}$ in the $12-50 \mathrm{~km}$ (Figure 5) and 23-50 km partial column, and MERRA PV maps showing a large filament over Toronto at all four levels (Figure 8) due to a vortex split during a major stratospheric warming [Jayanarayanan et al., 2011], but there are no $\mathrm{O}_{3}$ observations by OSIRIS on this date nor is there GMI output. $\mathrm{O}_{3}$ total column observations from EP/TOMS exist (from ozoneaq.gsfc.nasa.gov) and are shown in Figure 8 (note the different orientation of the map). In this figure there is a large amount of $\mathrm{O}_{3}$ to the west of the polar vortex structure (over western Canada and over the Pacific ocean) which represents regular midlatitude
$\mathrm{O}_{3}$, but where the intrusion occurs (over Ontario and Quebec), the $\mathrm{O}_{3}$ total columns are reduced, in agreement with our ground-based measurements. The winter of 2002/2003 had appropriate conditions for chemical $\mathrm{O}_{3}$ loss inside the vortex through late January, as it was cold [ $W M O, 2007]$, and Arctic $\mathrm{O}_{3}$ depletion was reported [e.g., Christensen et al., 2005; Singleton et al., 2005; Jayanarayanan et al., 2011]. The $\mathrm{HCl}$ stratospheric column is also decreased (Figure 5), which is consistent with chemical ozone loss, as it implies that $\mathrm{Cl}$ is activated.

[50] On 6 February 2007 the CARE O $\mathrm{C}_{3} 12-50 \mathrm{~km}$ partial column is reduced (Figure 5). The MIMOSA and MERRA $\mathrm{PV}$ maps and the GMI $\mathrm{N}_{2} \mathrm{O}$ and $\mathrm{O}_{3}$ maps at $475 \mathrm{~K}$ (Figure 9) all show a large filament over our region, but the GMI $475 \mathrm{~K}$ map on 6 February 2007 has enhanced $\mathrm{O}_{3}$ compared to the surrounding midlatitudes. However, the GMI $575 \mathrm{~K}(\sim 23 \mathrm{~km}) \mathrm{O}_{3}$ map does show reduced $\mathrm{O}_{3}$ in both the vortex and filament. There is no OSIRIS coverage over the Northern Hemisphere during early February to compare with GMI, but Rösevall et al. [2007], Sonkaew et al. [2011], and Søvde et al. [2011] report significant Arctic $\mathrm{O}_{3}$ depletion that winter, including on the date of our observation at the $575 \mathrm{~K}$ level. Observations of $\mathrm{O}_{3}$ from MLS at $490 \mathrm{~K}$ (not shown) show vortex $\mathrm{O}_{3}$ that is comparable to midlatitude $\mathrm{O}_{3}$ (http://mls.jpl.nasa.gov/plots $/ \mathrm{mls} / \mathrm{mls}$ plot locator.php) consistent with the GMI $475 \mathrm{~K}$ map. The $\mathrm{O}_{3}$ total column map from OMI (from ozoneaq.gsfc.nasa.gov) is shown in Figure 9 and supports our ground-based measurements, as the $\mathrm{O}_{3}$ columns in the polar vortex region (including the filament over Ontario and Quebec) are smaller than the $\mathrm{O}_{3}$ columns at other midlatitudes (e.g., over the rest of Canada).

[51] In contrast to the events on 20 January 2003 and 6 February 2007 discussed above, polar intrusions on 23 

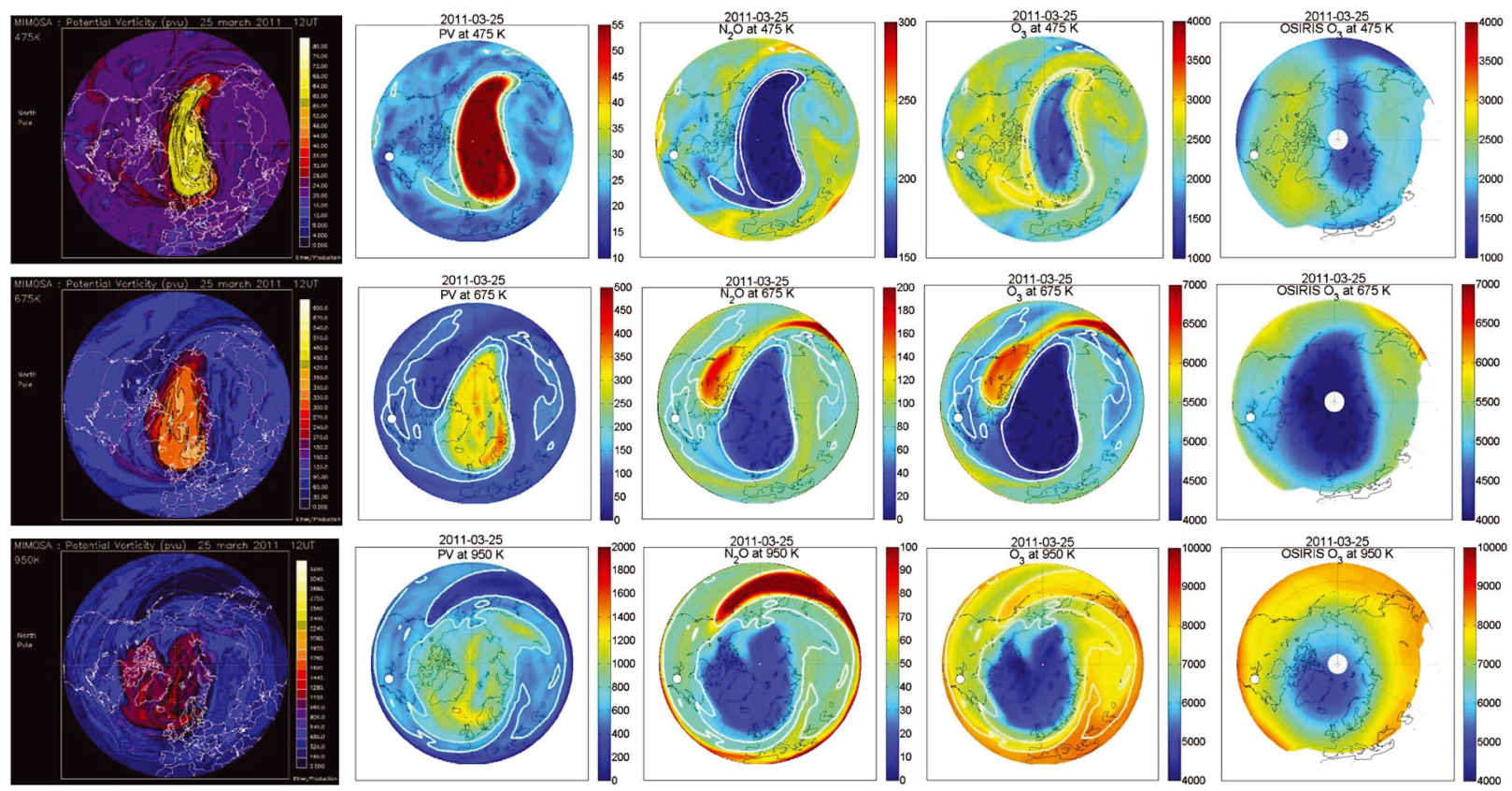

OMal Total Ozone for Mar 25, 2011

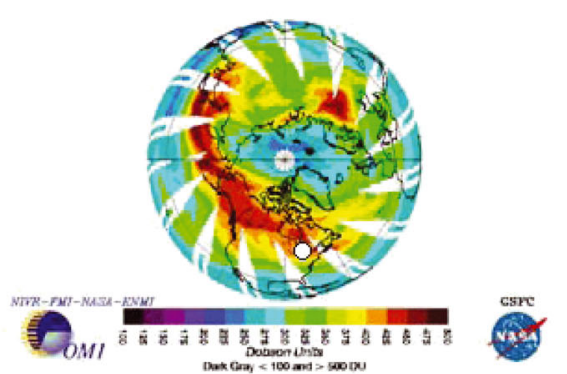

Figure 10. Polar intrusion event on 25 March 2011. (from left to right) MIMOSA and MERRA PV (both in pvu), GMI $\mathrm{N}_{2} \mathrm{O}$ and $\mathrm{O}_{3}$ (both in ppbv), and OSIRIS $\mathrm{O}_{3}$ (also in ppbv). (bottom) OMI $\mathrm{O}_{3}$ total column (note the different orientation). (from top to bottom) $475 \mathrm{~K}, 675 \mathrm{~K}$, and $950 \mathrm{~K}$. White circles denote the location of Toronto/Egbert. White contours denote the inner and outer vortex edge limits.

February 2007 and 23-25 March 2011 do not show reduced $\mathrm{O}_{3}$ columns (Figures 5 and 6), which might have been expected given the chemical $\mathrm{O}_{3}$ depletion observed in the polar vortex by Rösevall et al. [2007] in 2007 and Manney et al. [2011] in 2011. In these cases, $\mathrm{O}_{3}$ was not reduced in the vortex filaments, which extended over Toronto (e.g., the 25 March 2011 case shown in Figure 10, first and last rows). It would seem that the filaments were not $\mathrm{O}_{3}$ poor because $\mathrm{O}_{3}$ depletion was not uniform throughout the vortex. For example, at the end of March 2011, the vortex was $\mathrm{O}_{3}$ poor near the center but not around its edge (see $\mathrm{O}_{3}$ in top row of Figure 10). The filament originated from the edge region; therefore, the filament has enhanced $\mathrm{O}_{3}$ compared to midlatitude air. In contrast, on 6 February 2007 (discussed above), the $\mathrm{O}_{3}$-poor air is located near the edge of the polar vortex at $575 \mathrm{~K}$; hence, its filament is also $\mathrm{O}_{3}$ poor (Figure 9).

[52] The polar intrusion event on 23-25 March 2011 is shown for one day in Figure 10 at $675 \mathrm{~K}$ and $950 \mathrm{~K}$, which are the levels where the polar intrusion occurred, and $475 \mathrm{~K}$, which is approximately where the peak contribution to the $\mathrm{O}_{3}$ stratospheric column occurs. The OSIRIS $\mathrm{O}_{3}$ maps are also shown for this day, confirming the GMI results, and the OMI total column $\mathrm{O}_{3}$ is shown, confirming reduced $\mathrm{O}_{3}$ inside the polar vortex, but not in the filament that passed over Toronto.

\subsubsection{Impact of a Stratospheric Warming}

[53] Similar to January 2003 (Figure 8), January and February of 2009 had interesting polar vortex activity, when a major mid-winter warming occurred [Manney et al., 2009; Labitzke and Kunze, 2009], and the vortex split in two, one half passing over southern Ontario in early February. The maps in Figure 11 show the beginning of this breakup, and the polar vortex is already over Toronto as early as 16 January 2009. Figure 6 shows the effect on the FTIR columns. The $\mathrm{HCl}$ stratospheric column is decreased. The upper stratospheric $\mathrm{O}_{3}$ columns $(23-50 \mathrm{~km})$ were reduced, while the lower stratospheric $\mathrm{O}_{3}$ columns $(12-23 \mathrm{~km})$ were enhanced (not shown), resulting in the stratospheric $\mathrm{O}_{3}$ columns $(12-50 \mathrm{~km})$ being unchanged (shown in Figure 6). These results are consistent with the GMI modeled $\mathrm{O}_{3}$, though the OMI total column $\mathrm{O}_{3}$ appears to be slightly reduced in the polar vortex region (Figure 11).

\subsection{Vertical Structure of Polar Intrusion Events}

[54] Figure 12 shows the vertical extent of the 53 polar intrusion events in SPV. The vertical grey lines in Figure 12 

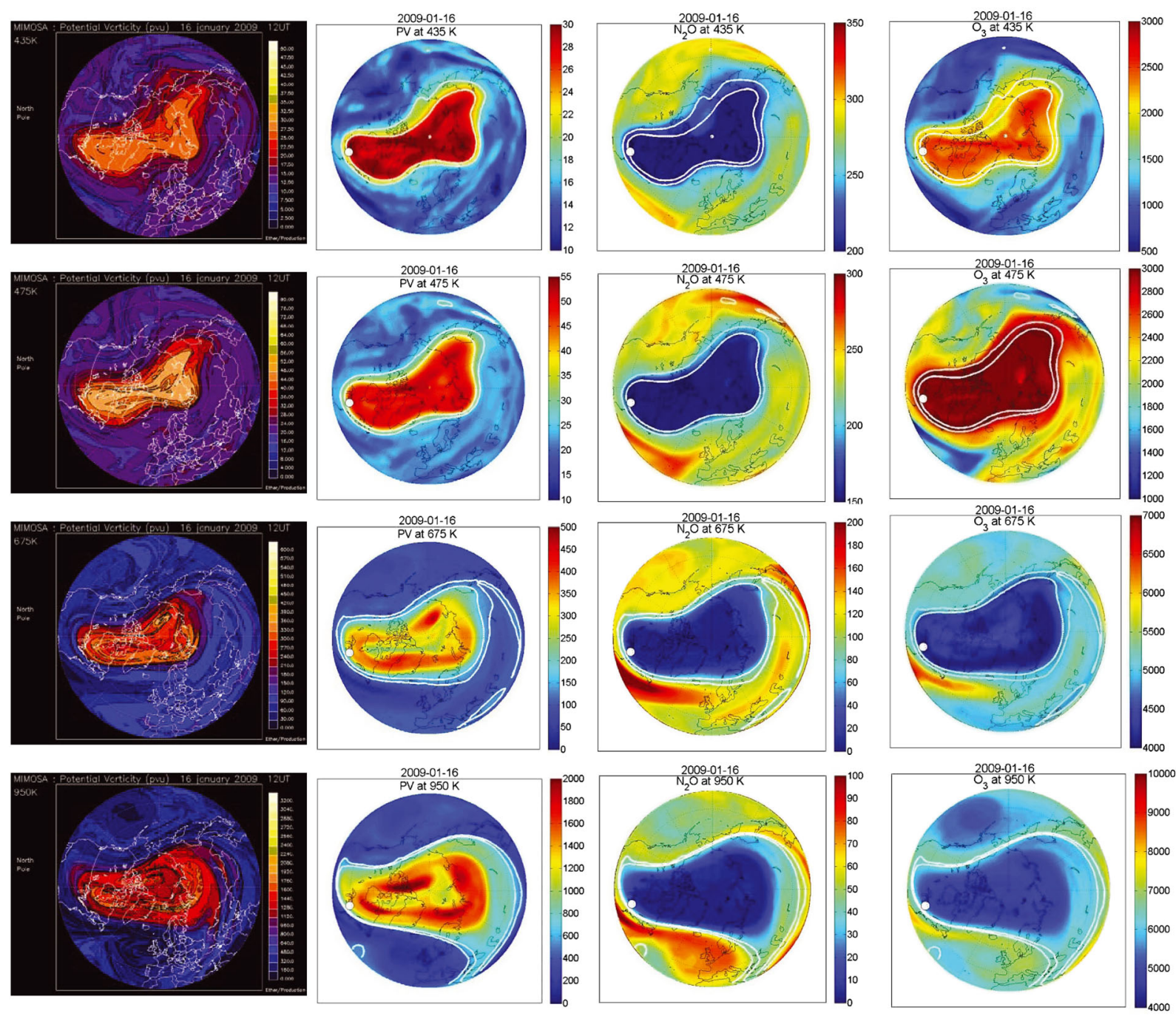

Figure 11. Polar intrusion event on 16 January 2009. (from left to right) MIMOSA and MERRA PV (both in pvu), GMI $\mathrm{N}_{2} \mathrm{O}$ and $\mathrm{O}_{3}$ (both in ppbv), and the OMI total $\mathrm{O}_{3}$ column map is also shown (note the different orientation). (from top to bottom) the intrusion is shown at $435 \mathrm{~K}, 475 \mathrm{~K}, 675 \mathrm{~K}$, and 950 $\mathrm{K}$. White circles denote the location of Toronto/Egbert. White contours denote the inner and outer vortex edge limits.

indicate the outer and inner polar vortex edges, as given by the $\mathrm{SPV}$ criterion described in section 3.3. The mean sPV profile from nonintrusion $\left(s P V<1.2 \times 10^{-4} \mathrm{~s}^{-1}\right)$ days and its standard deviation are the thick black lines shown for comparison. Most of the polar intrusion events have sPV values that are within the edge region, but at least half of our 53 events have even higher sPV values, putting them well inside the polar vortex at some part of the profile. In most cases, $\mathrm{SPV}$ tends to be large compared to the nonevent mean from about 370 to $1500 \mathrm{~K}$ (or 12 to $45 \mathrm{~km}$ ), which coincides with the vertical range over which the FTIR retrievals are sensitive (see Figure 1 and section 2.1.1).

[55] These results indicate that FTIR partial column measurements provide useful information for polar intrusion detection. Previous publications describing midlatitude polar intrusion events have presented trace gas vertical profiles from aircraft, lidar, and balloon-borne in situ measurements [Newman et al., 1996; Orsolini et al., 2001; Godin et al., 2002; Durry and Hauchecorne, 2005; Tripathi et al., 2006]. However, these aircraft, lidar, and balloon measurements were limited to the lower stratosphere (about $10-30 \mathrm{~km}$ or $350-800 \mathrm{~K}$ ), which may miss events that occur between 30 and $50 \mathrm{~km}(\sim 800-2200 \mathrm{~K})$ (e.g., the 14 May 2003 and 14 December 2004 events detected in this studyred and dark green lines in Figure 12, respectively). For $\mathrm{HF}, \mathrm{HCl}, \mathrm{N}_{2} \mathrm{O}$, and $\mathrm{O}_{3}$, the $30-50 \mathrm{~km}$ partial columns contain about $45 \%, 27 \%, 2 \%$, and $30 \%$ of the stratospheric (12-50 km) columns, respectively.

[56] The vertical thickness of the intrusions ranges from about $5 \mathrm{~km}$ (e.g., 3 March 2005-orange line in Figure 12) to about 30 km (e.g., 16 January 2009—pink line in Figure 12), and there is often more than one peak in the vertical profiles of sPV (e.g., 27 October 2010-light green line in Figure 12), indicating vortex filament structures occurring at more than one level. These results for vertical extent are consistent with Newman et al. [1996] who observed shallow intrusions at midlatitudes in the lower stratosphere, as well as with the studies by Orsolini [1995], Orsolini et al. 


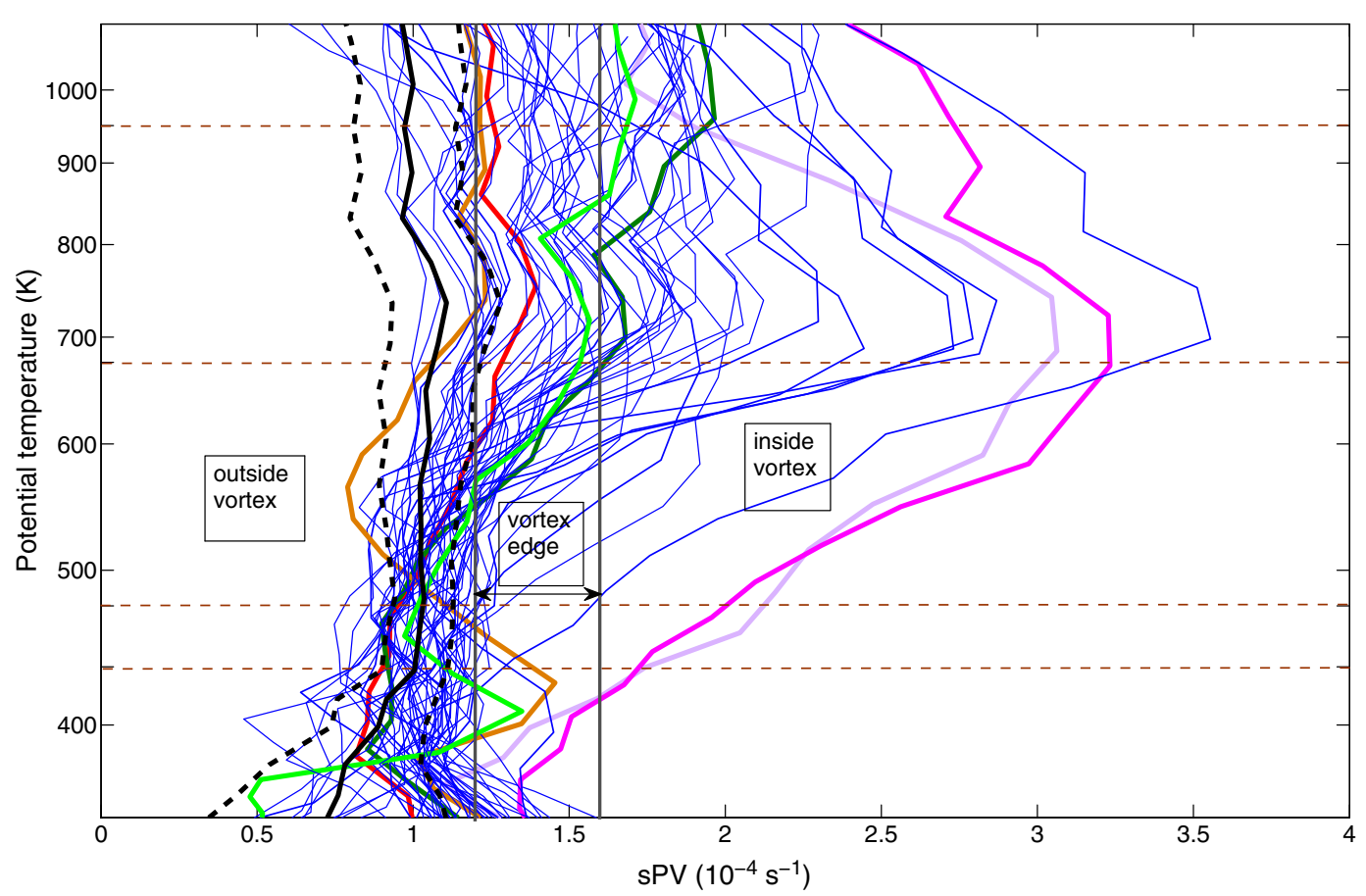

Figure 12. Scaled potential vorticity over Toronto during the 53 polar intrusion events derived from MERRA (blue and colored lines). The grey vertical lines indicate the outer and inner polar vortex edges. The horizontal dashed lines are the four vertical levels at which sPV was sampled in the time series. The thick black line and dashed black lines are the mean sPV profile from all nonintrusion days and its standard deviation, respectively. The colored lines are sPV profiles from specific days that were discussed in sections 4.2 and 4.4: mauve $=20$ January 2003, red $=14$ May 2003, dark green $=14$ December 2004, orange $=3$ March 2005, pink $=16$ January 2009, and light green $=27$ October 2010 .

[1997], and Schoeberl and Newman [1995] who observed and modeled both shallow and deep polar vortex filaments throughout the stratosphere.

\section{Conclusions}

[57] We have presented the TAO and CARE ground-based FTIR time series of stratospheric $\mathrm{HF}, \mathrm{HCl}, \mathrm{O}_{3}$, and $\mathrm{N}_{2} \mathrm{O}$ partial columns measured from January 2002 to March 2013 and have used these results, along with the SPV analysis, to identify 53 polar intrusion events over the densely populated Toronto area. All 11 years had at least 2 days with a polar intrusion event detected in enhanced HF columns, with four events per year being the average. Most of the events were detected in the late fall, winter, or early spring, when the polar vortex was formed or distorted, rapidly changing, and frequently shedding filaments. These conditions commonly occur throughout Arctic fall and winter [e.g., Manney et al., 2000]. To our knowledge, this is the first study to use ground-based FTIR column measurements to identify multiple polar intrusions over the course of a decade over a particular midlatitude region and to examine the impact of intrusions on the stratospheric columns of four different trace gases.

[58] FTIR measurements of HF columns were useful for detecting polar vortex intrusions; the HF stratospheric columns were enhanced during $100 \%$ of the lower stratosphere $(435 \mathrm{~K}$ and $475 \mathrm{~K})$ polar vortex $\left(\mathrm{sPV}>1.6 \times 10^{-4} \mathrm{~s}^{-1}\right)$ overpasses. When the upper stratosphere ( $675 \mathrm{~K}$ and $950 \mathrm{~K})$ polar vortex intrusions are also included, $40 \%$ of HF strato- spheric columns were enhanced, as the upper stratosphere contributes less overall to the HF columns. However, $40 \%$ is still a significant amount detected by HF column measurements. When the polar vortex edge $(\mathrm{sPV}>1.2 \times$ $10^{-4} \mathrm{~s}^{-1}$ ) overpasses are also included, the percentage drops to $30 \%(25 \%)$ for the lower (upper) stratosphere events.

[59] Most of the late fall, winter, and early spring variability in the TAO HF time series (Figure 7) can be explained by transient polar intrusion events, although the magnitude of the effect varies from year to year. The effect on the $\mathrm{O}_{3}$ time series (FTIR and OSIRIS) is irregular (Figure 7, Table 3); most of the time, there is a small increase in $\mathrm{O}_{3}$ during an event, even when there is $\mathrm{O}_{3}$ depletion inside the vortex. The vortex filaments often do not share the $\mathrm{O}_{3}$-depleted state of the vortex (e.g., the unprecedented $\mathrm{O}_{3}$ loss in 2011 did not cause a decrease in Toronto $\mathrm{O}_{3}$ columns). Based on our results and the Marchand et al. [2003] study, $\mathrm{O}_{3}$ depletion over Toronto is more likely to occur during a vortex excursion, and these are rarer than filaments.

[60] The vertical profiles of sPV (Figure 12) show that the intrusions can occur at varying altitudes and span various vertical ranges. While the FTIR retrievals cannot resolve those features, the sensitivity in the $12-50 \mathrm{~km}$ range is sufficient to see variability in the stratospheric columns caused by these polar intrusion events, including mid-toupper stratospheric events, which are not measurable with sondes, lidar, aircraft, and in situ instruments.

[61] FTIR spectroscopy is capable of measuring numerous polar vortex tracers and stratospheric gases important for $\mathrm{O}_{3}$ chemistry over long periods. There are 14 NDACC 
sites north of $40^{\circ} \mathrm{N}$; many of which have been taking observations for more than a decade (e.g., http://www.acd.ucar. edu/irwg/). Based on the results of this study, these data sets should also provide evidence of polar intrusion events and afford an opportunity to study the accuracy of their representation in models.

[62] Acknowledgments. Funding for this work was provided by the Natural Sciences and Engineering Research Council of Canada, the Canadian Space Agency (CSA), and Environment Canada. The TAO measurements have been supported in the past by the Canadian Foundation for Climate and Atmospheric Sciences, ABB Bomem, the Canada Foundation for Innovation, the Ontario Research and Development Challenge Fund, the Premier's Research Excellence Award, and the University of Toronto. We also wish to thank the many students, postdocs, and interns who have contributed to TAO data acquisition since 2001.

[63] The CARE DA8 was operated by Environment Canada. OSIRIS is onboard Odin, a Swedish-led satellite project funded jointly by Sweden (SNSB), Canada (CSA), Finland (TEKES), and France (CNES) and supported since 2007 by the third party mission program of the European Space Agency. EP/TOMS and OMI maps were prepared by the Ozone Processing Team of NASA/Goddard Space Flight Center. The MERRA data used in this effort were acquired as part of the activities of NASA's Science Mission Directorate and are archived and distributed by the Goddard Earth Sciences Data and Information Services Center. The authors acknowledge Ether, the French data center for atmospheric chemistry, created and codirected by the Centre National d'Études Spatiales (CNES) and the National Institute of Sciences of the Universe (INSU-CNRS) for the provision of MIMOSA data. We thank Susan E. Strahan (NASA Goddard Earth Science and Technology Center) for the GMI model output. Work at the Jet Propulsion Laboratory, California Institute of Technology was done under contract with the National Aeronautic and Space Administration.

\section{References}

Adams, C., et al. (2012), Severe 2011 ozone depletion assessed with 11 years of ozone, $\mathrm{NO}_{2}$, and $\mathrm{OClO}$ measurements at $80^{\circ} \mathrm{N}$, Geophys. Res. Lett., 39, L05806, doi:10.1029/2011GL050478.

Adams, C., et al. (2013a), Characterization of Odin-OSIRIS ozone profiles with the SAGE II dataset, Atmos. Meas. Tech., 6, 1447-1459, doi:10.5194/amt-6-1447-2013.

Adams, C., A. E. Bourassa, V. Sofieva, L. Froidevaux, C. A. McLinden, D. Hubert, J.-C. Lambert, C. E. Sioris, and D. A. Degenstein (2013b), Assessment of Odin-OSIRIS ozone measurements from 2001 to the present using MLS, GOMOS, and ozone sondes, Atmos. Meas. Tech. Discuss., 6, 3819-3857, doi:10.5194/amtd-6-3819-2013.

Andrews, D. G., J. R. Holton, and C. B. Leovy (1987), Middle Atmosphere Dynamics, Academic Press, London.

Balis, D., et al. (2011), Observed and modelled record ozone decline over the Arctic during winter/spring, Geophys. Res. Lett., 38, L23801, doi:10.1029/2011GL049259.

Brasseur, G. P., J. J. Orlando, and G. S. Tyndall (1999), Atmospheric Chemistry and Global Change, Oxford Univ. Press, New York.

Butchart, N., and E. E. Remsberg (1986), The area of the stratospheric polar vortex as a diagnostic for tracer transport on an isentropic surface, $J$. Atmos. Sci., 43, 1319-1339.

Chipperfield, M. P., et al. (1997), On the use of HF as a reference for the comparison of stratospheric observations and models, J. Geophys. Res., 102(D11), 12,901-12,919, doi:10.1029/96JD03964.

Christensen, T., et al. (2005), Vortex-averaged Arctic ozone depletion in the winter 2002/2003, Atmos. Chem. Phys., 5, 131-138, doi:10.5194/acp-5131-2005.

Coffey, M. T., et al. (2008), Airborne Fourier transform spectrometer observations in support of EOS Aura validation, J. Geophys. Res., 113, D16S42, doi:10.1029/2007JD008833.

Degenstein, D. A., A. E. Bourassa, C. Z. Roth, and E. J. Llewellyn (2009), Limb scatter ozone retrieval from 10 to $60 \mathrm{~km}$ using a multiplicative algebraic reconstruction technique, Atmos. Chem. Phys., 9, 6521-6529, doi:10.5194/acp-9-6521-2009.

Duchatelet, P., et al. (2009), An approach to retrieve information on the carbonyl fluoride $\left(\mathrm{COF}_{2}\right)$ vertical distributions above Jungfraujoch by FTIR multi-spectrum multi-window fitting, Atmos. Chem. Phys., 9, 9027-9042, doi:10.5194/acp-9-9027-2009.

Duncan, B. N., S. E. Strahan, Y. Yoshida, S. D. Steenrod, and N. Livesey (2007), Model study of the cross-tropopause transport of biomass burning pollution, Atmos. Chem. Phys., 7, 3713-3736, doi:10.5194/acp-73713-2007.
Dunkerton, T. J., and D. P. Delisi (1986), Evolution of potential vorticity in the winter stratosphere of January-February 1979, J. Geophys. Res. 91 (D1), 1199-1208, doi:10.1029/JD091iD01p01199.

Durry, G., and A. Hauchecorne (2005), Evidence for long-lived polar vortex air in the mid-latitude summer stratosphere from in situ laser diode CH4 and H2O measurements, Atmos. Chem. Phys., 5, 1467-1472, doi:10.5194/acp-5-1467-2005.

Eyring, V., et al. (2007), Multimodel projections of stratospheric ozone in the 21st century, J. Geophys. Res., 112, D16303, doi:10.1029/ 2006JD008332.

Fairlie, T. D. A., R. B. Pierce, W. L. Grose, G. Lingenfelser, M. Loewenstein, and J. R. Podolske (1997), Lagrangian forecasting during ASHOE/MAESA: Analysis of predictive skill for analyzed and reverse-domain-filled potential vorticity, J. Geophys. Res., 102 (D11), 13,169-13,182, doi:10.1029/96JD03507.

Godin, S., M. Marchand, A. Hauchecorne, and F. Lefèvre (2002), Influence of Arctic polar ozone depletion on lower stratospheric ozone amounts at Haute-Provence Observatory $\left(43.92^{\circ} \mathrm{N}, 5.71^{\circ} \mathrm{E}\right), J$. Geophys. Res. 107(D20), 8272, doi:10.1029/2001JD000516.

Harvey, V. L., R. B. Pierce, T. D. Fairlie, and M. H. Hitchman (2002), A climatology of stratospheric polar vortices and anticyclones, J. Geophys. Res., 107(D20), 4442, doi:10.1029/2001JD001471.

Hauchecorne, A., S. Godin, M. Marchand, B. Heese, and C. Souprayen (2002), Quantification of the transport of chemical constituents from the polar vortex to midlatitudes in the lower stratosphere using the high-resolution advection model MIMOSA and effective diffusivity, $J$. Geophys. Res., 107(D20), 8289, doi:10.1029/2001JD000491.

Hoskins, B. J., M. E. McIntyre, and A. W. Robertson (1985), On the use and significance of isentropic potential vorticity maps, $Q . J$. R. Meteorol. Soc., 111, 877-946, doi:10.1002/qj.49711147002.

Jayanarayanan, K., A. Kleinbohl, M. Sinnhuber, H. Bremer, H. Kullmann, J. Notholt, S. Godin-Beekmann, O. Tripathi, and G. Nikulin (2011), Arctic ozone depletion in 20020-2003 measured by ASUR and comparison with POAM observations, J. Geophys. Res., 116, D22305, doi:10.1029/ 2011JD016020.

Kagawa, A., Y. Kasai, N. B. Jones, M. Yamamori, K. Seki, F. Murcray, Y. Murayama, K. Mizutani, and T. Itabe (2007), Characteristics and error estimation of stratospheric ozone and ozone-related species over Poker Flat $\left(65^{\circ} \mathrm{N}, 147^{\circ} \mathrm{W}\right)$, Alaska observed by a ground-based FTIR spectrometer from 2001 to 2003, Atmos. Chem. Phys., 7, 3791-3810, doi:10.5194/acp-7-3791-2007.

Keckhut, P., C. David, M. Marchand, S. Bekki, J. Jumelet, A. Hauchecorne, and M. Höpfner (2007), Observation of polar stratospheric clouds down to the Mediterranean coast, Atmos. Chem. Phys., 7, 5275-5281, doi:10.5194/acp-7-5275-2007.

Konopka, P., J.-U. Grooß, S. Bausch, R. Müller, D. S. McKenna, O. Morgenstern, and Y. Orsolini (2003), Dynamics and chemistry of vortex remnants in late Arctic spring 1997 and 2000: Simulations with the Chemical Lagrangian Model of the Stratosphere (CLaMS), Atmos. Chem. Phys., 3, 839-849, doi:10.5194/acp-3-839-2003.

Labitzke, K. and M. Kunze (2009), On the remarkable Arctic winter in 2008/2009, J. Geophys. Res., 114, D00I02, doi:10.1029/2009JD012273.

Leovy, C. B., C.-R. Sun, M. Hitchman, E. E. Remsburg, J. M. Russell III, L. L. Gordley, J. C. Gille, and L. V. Lyjak (1985), Transport of ozone in the middle stratosphere: Evidence for planetary wave breaking, J. Atmos. Sci., 42, 230-244, doi:10.1175/1520-0469(1985)042< 0230:TOOITM $>2.0 . \mathrm{CO} ; 2$.

Lindenmaier, R., R. Batchelor, K. Strong, H. Fast, F. Goutail, F. Kolonjari, C. T. McElroy, R. Mittermaier, and K. Walker (2010), An evaluation of infrared microwindows for ozone retrievals using the Eureka Bruker 125HR Fourier transform spectrometer, J. Quant. Spectrosc. Radiat. Transfer., 111, 569-585, doi:10.1016/j.jqsrt.2009. 10.013

Lindenmaier, R. et al. (2012), Unusually low ozone, $\mathrm{HCl}$, and $\mathrm{HNO}_{3}$ column measurements at Eureka, Canada during winter/spring 2011, Atmos. Chem. Phys., 12, 3821-3835, doi:10.5194/acp-12-3821-2012.

Llewellyn, E., et al. (2004), The OSIRIS instrument on the Odin spacecraft, Can. J. Phys., 82, 411-422, doi:10.1139/p04-005.

Manney, G. L., R. W. Zurek, A. O'Neill, and R. Swinbank (1994), On the motion of air through the stratospheric polar vortex, $J$. Atmos. Sci., 51, 2973-2994, doi:10.1175/1520-0469(1994)051<2973: OTMOAT $>2.0 . \mathrm{CO} ; 2$

Manney, G. L., J. C. Bird, D. P. Donovan, T. J. Duck, J. A. Whiteway, S. R. Pal, and A. I. Carswell (1998), Modeling ozone laminae in ground-based Arctic wintertime observations using trajectory calculations and satellite data, J. Geophys. Res., 103(D5), 5797-5814, doi:10.1029/97JD03449.

Manney, G. L., H. A. Michelsen, F. W. Irion, M. R. Gunson, G. C. Toon, and A. E. Roche (2000), Lamination and polar vortex development in fall from ATMOS long-lived trace gases observed during November 1994, $J$ Geophys. Res., 105(D23), 29,023-29,038, doi:10.1029/2000JD900428. 
Manney, G. L., et al. (2007), Solar occultation satellite data and derived meteorological products: Sampling issues and comparisons with Aura Microwave Limb Sounder, J. Geophys. Res., 112, D24550, doi:10.1029/2007JD008709.

Manney, G. L., M. J. Schwartz, K. Krüger, M. L. Santee, S. Pawson, J. N. Lee, W. H. Daffer, R. A. Fuller, and N. J. Livesey (2009), Aura Microwave Limb Sounder observations of dynamics and transport during the record-breaking 2009 Arctic stratospheric major warming, Geophys. Res. Lett., 36, L12815, doi:10.1029/2009GL038586.

Manney, G. L., et al. (2011), Unprecedented Arctic ozone loss in 2011, Nature, 478, 469-475, doi:10.1038/nature10556.

Marchand, M., S. Godin, A. Hauchecorne, F. Lefèvre, S. Bekki, and M. Chipperfield (2003), Influence of polar ozone loss on northern midlatitude regions estimated by a high-resolution chemistry transport model during winter 1999/2000, J. Geophys. Res., 108(D5), 8326 , doi:10.1029/2001JD000906.

McIntyre, M. E., and T. N. Palmer (1984), The "surf zone" in the stratosphere, J. Atmos. Terr. Phys., 9, 825-849.

Mellqvist, J., B. Galle, T. Blumenstock, F. Hase, D. Yashcov, J. Notholt, B. Sen, J.-F. Blavier, G. C. Toon, and M. P. Chipperfield (2002), Groundbased FTIR observations of chlorine activation and ozone depletion inside the Arctic vortex during the winter of 1999/2000, J. Geophys. Res., 107(D20), doi:10.1029/2001JD001080.

Millard, G. A., A. M. Lee, and J. A. Pyle (2003), A model study of the connection between polar and midlatitude ozone loss in the Northern Hemisphere lower stratosphere, J. Geophys. Res., 108(D5), 8323, doi:10.1029/2001JD000899.

Murtagh, D., et al. (2002), An overview of the Odin atmospheric mission, Can. J. Phys., 80, 309-319, doi:10.1139/p01-157.

Nash, E. R., P. A. Newman, J. E. Rosenfield, and M. R. Schoeberl (1996), An objective determination of the polar vortex using Ertel's potential vorticity, J. Geophys. Res., 101(D5), 9471-9478, doi:10.1029/96JD00066.

Newman, P. A., et al. (1996), Measurements of polar vortex air in midlatitudes, J. Geophys. Res., 101(D8), 12,879-12,891, doi:10.1029/ 95JD03387.

Orsolini, Y. J. (1995), On the formation of ozone laminae at the edge of the Arctic polar vortex, Q. J. R. Meteorol. Soc., 121, 1923-1941, doi:10.1002/qj.49712152808.

Orsolini, Y. J., G. Hansen, U. Hoppe, G. L. Manney, and K. Fricke (1997), Dynamical modelling of wintertime Lidar observations in the Arctic: Ozone laminae and ozone depletion, Q. J. R. Meteorol. Soc., 123, 785-800, doi:10.1002/qj.49712353913.

Orsolini, Y. J., G. L. Manney, A. Engel, J. Ovarlez, C. Claud, and L. Coy (1998), Layering in stratospheric profiles of long-lived trace species: Balloon-borne observations and modeling, J. Geophys. Res., 103(D5), 5815-5825, doi:10.1029/97JD03131.

Orsolini, Y. J., and W. B. Grant (2000), Seasonal formation of nitrous oxide laminae in the mid and low latitude stratosphere, Geophys. Res. Lett., 27(D8), 1119-1122, doi:10.1029/1999GL011172.

Orsolini, Y. J., G. Hansen, G. L. Manney, N. J. Livesey, and U.-P. Hoppe (2001), Lagrangian reconstruction of ozone column and profile at the Arctic Lidar Observatory for Middle Atmosphere Research (ALOMAR) throughout winter and spring 1997-98, J. Geophys. Res., 106(D9), 10,011-10,021, doi:10.1029/2000JD900659.

Pierce, R. B., and T. D. A. Fairlie (1993), Chaotic advection in the stratosphere: Implications for the dispersal of chemically perturbed air from the polar vortex, J. Geophys. Res., 98(D10), 18,589-18,595, doi:10.1029/93JD01619.

Pougatchev, N., B. Connor, and C. Rinsland (1995), Infrared measurements of the ozone vertical distribution above Kitt Peak, J. Geophys. Res., 100(D8), 16,689-16,697, doi:10.1029/95JD01296.

Rienecker, M. M., et al. (2011), MERRA: NASA's Modern-Era retrospective analysis for research and applications, J. Clim., 24 3624-3628.

Rinsland, C. P., et al. (1998), Nothern and southern hemisphere groundbased infrared spectroscopic measurements of tropospheric carbon monoxide and ethane, J. Geophys. Res., 103(D21), 28,197-28,217, doi:10.1029/98JD02515.

Rodgers, C. D. (2000), Inverse Methods For Atmospheric Sounding: Theory and Practice (Series on Atmospheric, Oceanic and Planetary Physics), vol. 2, World Scientific Publishing Co. Pte. Ltd., New Jersey.

Rösevall, J. D., D. P. Murtagh, and J. Urban (2007), Ozone depletion in the 2006/2007 Arctic winter, Geophys. Res. Lett., 34, L21809, doi:10.1029/2007GL030620.

Rösevall, J. D., D. P. Murtagh, J. Urban, W. Feng, P. Eriksson, and S. Brohede (2008), A study of ozone depletion in the 2004/2005 Arctic winter based on data from Odin/SMR and Aura/MLS, J. Geophys. Res., 113, D13301, doi:10.1029/2007JD009560.
Rothman, L. S., et al. (2009), The HITRAN 2008 molecular spectroscopic database, J. Quant. Spectrosc. Radiat. Transfer., 110, 533-572.

Schoeberl, M. R., L. R. Lait, P. A. Newman, and J. E. Rosenfield (1992), The structure of the polar vortex, J. Geophys. Res., 97(D8), 7859-7882, doi:10.1029/91JD02168.

Schoeberl, M. R., M. Luo, and J. E. Rosenfield (1995), An analysis of the Antarctic Halogen Occultation Experiment trace gas observations, $J$. Geophys. Res., 100(D3), 5159-5172, doi:10.1029/94JD02749.

Schoeberl, M. R., and P. A. Newman (1995), A multiple-level trajectory analysis of vortex filaments, J. Geophys. Res., 100(D12), 25,801-25,815, doi:10.1029/95JD02414.

Singleton, C. S., C. E. Randall, M. P. Chipperfield, S. Davies, W. Feng, R. M. Bevilacqua, K. W. Hoppel, M. D. Fromm, G. L. Manney, and V. L. Harvey (2005), 2002-2003 Arctic ozone loss deduced from POAM III satellite observations and the SLIMCAT chemical transport model, Atmos. Chem. Phys., 5, 597-609, doi:10.5194/acp-5-597-2005.

Sonkaew, T., C. von Savigny, K.-U. Eichmann, M. Weber, A. Rozanov, H. Bovensmann, and J. P. Burrows (2011), Chemical ozone loss in Arctic and Antarctic polar winter/spring season derived from SCIAMACHY limb measurements 2002-2009, Atmos. Chem. Phys. Discuss., 11, 6555-6599, doi:10.5194/acpd-11-6555-2011.

Søvde, O. A., Y. J. Orsolini, D. R. Jackson, F. Stordal, I. S. A. Isaksen, and B. Rognerud (2011), Estimation of Arctic $\mathrm{O}_{3}$ loss during winter 2006/2007 using data assimilation and comparison with a chemical transport model, Q. J. R. Meteorol. Soc., 137, 118-128, doi:10.1002/ qj. 740 .

Strahan, S. E., B. N. Duncan, and P. Hoor (2007), Observationally derived transport diagnostics for the lowermost stratosphere and their application to the GMI chemistry and transport model, Atmos. Chem. Phys., 7, 2435-2445, doi:10.5194/acp-7-2435-2007.

Sutton, R. T., H. Maclean, R. Swinbank, A. O'Neill, and F. W. Taylor (1994), High-resolution stratospheric tracer fields estimated from satellite observations using Lagrangian trajectory calculations, J. Atmos. Sci., 51, 2995-3005.

Taylor, J. R., K. Strong, C. A. McLinden, D. A. Degenstein, and C. S. Haley (2007), Comparison of OSIRIS stratospheric $\mathrm{NO}_{2}$ and $\mathrm{O}_{3}$ measurements with ground-based Fourier transform spectrometer measurements at the Toronto Atmospheric Observatory, Can. J. Phys., 85, 1301-1316, doi:10.1139/P07-144.

Taylor, J. R., D. Wunch, C. Midwinter, A. Wiacek, J. R. Drummond, and K. Strong (2008), An extended intercomparison of simultaneous ground-based Fourier transform infrared spectrometer measurements at the Toronto Atmospheric Observatory, J. Quant. Spectrosc. Radiat. Transfer., 109, 2244-2260, doi:10.1016/j.jqsrt.2008.03.011.

Toon, G. C., J.-F. Blavier, B. Sen, R. J. Salawitch, G. B. Osterman, J. Notholt, M. Rex, C. T. McElroy, and J. M. Russell III (1999) Ground-based observations of Arctic $\mathrm{O}_{3}$ loss during spring and summer 1997, J. Geophys. Res., 104(D21), 26,497-26,510, doi:10.1029/ 1999JD900745.

Tripathi, O. P., T. Leblanc, I. S. McDermid, F. Lefèvre, M. Marchand, and A. Hauchecorne (2006), Forecast, measurement, and modeling of an unprecedented polar ozone filament event over Mauna Loa Observatory, Hawaii, J. Geophys. Res., 111, D20308, doi:10.1029/ 2006JD007177.

Vigouroux, C., et al. (2008), Evaluation of tropospheric and stratospheric ozone trends over Western Europe from ground-based FTIR network observations, Atmos. Chem. Phys., 8, 6865-6886, doi:10.5194/acp-86865-2008

Waugh, D. W., et al. (1994), Transport out of the lower stratospheric Arctic vortex by Rossby wave breaking, J. Geophys. Res., 99(D1), 1071-1088, doi:10.1029/93JD02556.

Wiacek, A. (2006), First trace gas measurements using Fourier transform infrared solar absoption spectroscopy at the University of Toronto Atmospheric Observatory, PhD thesis, Department of Physics, University of Toronto.

Wiacek, A., J. R. Taylor, K. Strong, R. Saari, and T. E. Kerzenmacher (2007), Ground-based solar absorption FTIR spectroscopy: Characterization of retrievals and first results from a novel optical design instrument at a new NDACC complementary station, J. Atmos. Oceanic Tech., 24, 432-448, doi:10.1175/JTRCH1962.1.

WMO, (2007), World Meteorological Organization Scientific Assessment of Ozone Depletion: 2006, WMO Global Ozone Research and Monitoring Project-Report 50, Geneva, Switzerland.

Wunch, D., J. R. Taylor, D. Fu, P. F. Bernath, J. R. Drummond, C. Midwinter, K. Strong, and K. A. Walker (2007), Simultaneous groundbased observations of $\mathrm{O}_{3}, \mathrm{HCl}, \mathrm{N}_{2} \mathrm{O}$, and $\mathrm{CH}_{4}$ over Toronto, Canada by three Fourier transform spectrometers with different resolutions, Atmos. Chem. Phys., 7, 1275-1292, doi:10.5194/acp-7-1275-2007. 